\title{
CAN CARBON NANOFIBERS AFFECT ANUROFAUNA? STUDY INVOLVING NEOTROPICAL Physalaemus cuvieri (Fitzinger, 1826) TADPOLES
}

\author{
Abraão Tiago Batista Guimarães ${ }^{1,2}$, Fernanda Neves Estrela ${ }^{1,2}$, Aline Sueli de Lima Rodrigues ${ }^{1}$, \\ Rafael Henrique Nóbrega ${ }^{3}$, Ives Charlie-Silva ${ }^{4}$, Guilherme Malafaia ${ }^{1,2,6}$ \#
}

${ }^{1}$ Post-Graduation Program in Biotechnology and Biodiversity, Federal University of Goiás, Goiânia, Brazil.

${ }^{2}$ Biological Research Laboratory, Goiano Federal Institute - Urutaí Campus, Urutaí, Brazil

${ }^{3}$ Reproductive and Molecular Biology Group, Morphology Department, São Paulo State University, Botucatu, Brazil.

${ }^{4}$ Department of Pharmacology, Institute of Biomedical Sciences, University of São Paulo, São Paulo, Brazil.

$4{ }^{5}$ Post-Graduation Program in Cerrado Natural Resources Conservation, Goiano Federal University 5 Urutaí Campus, Urutaí, Brazil

${ }^{6}$ Post-Graduation Program in Ecology and Natural Resources Conservation, Federal University of 7 Uberlândia, Uberlândia, Brazil.

\#Corresponding Author: Biological Research Laboratory, Goiano Federal Institution - Urutaí Campus. Rodovia Geraldo Silva Nascimento, 2,5 km, Zona Rural, Urutaí, GO, Brazil. CEP: 75790 000. Phone number: +55 643465 1995. E-mail: guilhermeifgoiano@gmail.com 


\section{ABSTRACT}

25 Although carbon nanotubes' (CNTs) toxicity in different experimental systems (in vivo and in vitro) is known, little is known about the toxic effects of carbon nanofibers (CNFs) on aquatic vertebrates. We herein investigated the potential impact of CNFs (1 and $10 \mathrm{mg} / \mathrm{L}$ ) by using Physalaemus cuvieri tadpoles as experimental model. CNFs were able to induce nutritional deficit in animals after 48-h exposure to them, and this finding was inferred by reductions observed in body concentrations of total soluble carbohydrates, total proteins, and triglycerides. The increased production of hydrogen peroxide, reactive oxygen species and thiobarbituric acid reactive substances in tadpoles exposed to CNFs has suggested REDOX homeostasis change into oxidative stress. This process was correlated to the largest number of apoptotic and necrotic cells in the blood of these animals. On the other hand, the increased superoxide dismutase and catalase activity has suggested that the antioxidant system of animals exposed to CNFs was not enough to maintain REDOX balance. In addition, $\mathrm{CNFs}$ induced increase in acetylcholinesterase and butyrylcholinesterase activity, as well as changes in the number of neuromats evaluated on body surface (which is indicative of the neurotoxic effect of nanomaterials on the assessed model system). To the best of our knowledge, this is the first report on the impact of CNFs on amphibians; therefore, it broadened our understanding about ecotoxicological risks associated with their dispersion in freshwater ecosystems and possible contribution to the decline in the populations of anurofauna species. 


\section{INTRODUCTION}

The recent scientific and technological development, and the invention of nanomaterials have allowed the creation and production of highly promising and advantageous materials that have been applied to address several challenges associated with conventional Science (Bhagyaraj \& Oluwafemi, 2018). Nanomaterials are gaining more and more interest given their unique properties and potential use in a wide range of technological applications. Recent studies have gathered vast information on the use of these materials by the food (Chaudhary et al., 2020; Shafiq et al., 2020), cosmetics (Fytianos et al., 2020; Singh et al., 2020) and civil construction sectors ( Firoozi et al., 2020; Singh, 2020), as well as in the manufacture of personal care (Keller et al., 2014; Kaul et al., 2018; Aziz et al., 2019), electronic (Zeb et al., 2019), medicinal and pharmaceutical (Velu et al., 2020; Das et al., 2020; Siddique \& Chow, 2020; Kumar et al., 2020) and industrial products (Thomas et al., 2019; Palit \& Hussain, 2020), and in different environmental sciences fields (Taran et al., 2020).

Carbon nanofibers (CNFs) that have conductivity and stability similar to that of carbon nanotubes (CNTs) (Lake \& Lake, 2014; Mohamed et al., 2019; Yadav et al., 2020) are among the most prominent nanomaterials in recent years. The main features of CNFs distinguishing them from CNTs is the stacking of graphene sheets at different shapes. These sheets produce more edge sites on the outer wall of CNFs than CNTs, and it makes the electron transfer of electroactive analytes easier (Yadav et al., 2020). However, CNFs' application has mainly focused on catalyst supports (Din et al., 2020), gas-storage systems (Conte et al., 2020), polymer reinforcements (Abdo et al., 2020), probe tips (Cui et al., 2004; Goto et al., 2014) and biosensor development, due to their unique physical and chemical properties (good electrical conductivity, high surface area, biocompatibility, inherent and induced chemical functionalities, and easy manufacture) (Saunier et al., 2020; Senthamizhan et al., 2020).

However, the assessment of ecological risks remain an incipient field involving CNFs, despite their dispersion and distribution in ecosystems - studies carried out with CNTs are much more numerous and comprehensive (Freixa et al., 2018; Gomes et al., 2021). Few investigations with CNFs include assays (Magrez et al., 2006; Brown et al., 2007; Jensen et al., 2012; Kalman et al., 2019) or experiments in vitro with invertebrates (Lee et al., 2015) or mammals (DeLorme et al., 2012; Jensen et al., 2012; Warheit, 2019). A small portion of studies in vivo has evaluated the effects of these nanomaterials on aquatic freshwater organisms (Chaika et al., 2020; Gomes et al., 2021; Montalvão et al., 2021). However, there is still an important gap in assessments on risk factors posed to, and physiological changes induced by, these compounds in aquatic organisms. Chaika et al. (2020) assessed CNF effects on the digestive system of different freshwater invertebrates 
79 (Families: Gammaridae, Ephemerellidae and Chironomidae), but they did not observe any 80 histopathotoxic effect on animals' gastrointestinal tract. In fact, these authors have shown the ability of Gammarus suifunensis to biodegrade CNFs (Chaika et al. 2020). Gomes et al. (2021) have evidenced that CNFs can be transferred by an experimental food chain (Eiseia fetida $>$ Danio rerio $>$ Oreochromis niloticus) and cause mutagenic and cytotoxic damage at the uppermost trophic level. Montalvão et al. (2021) reported that dragonfly larvae (Aphylla williamsoni) short-term exposure (48 h) to CNFs induced predictive changes in REDOX imbalance and neurotoxicity - this finding was inferred by suppressing the activity of acetylcholinesterase (AChE).

Therefore, the inconclusive character of the investigative scenario about CNFs' toxicity, as well as the gaps on knowledge about the impact of these nanomaterials on several groups of invertebrates and vertebrates are clear factors, so far. Amphibians are among these groups, but, although they have priceless ecological importance (Hocking \& Babbitt, 2014), they have never been the subject of investigations involving CNFs. Our knowledge about the toxicity of carbonbased nanomaterials (CNs) in amphibians is restricted to information available in reports by Saria et al. (2014) and Zhao et al. (2020). These authors were the first to show that the short-term exposure of Xenopus laevis tadpoles to multi-walled carbon nanotubes (MWCNTs) induced oxidative stress and caused damage to animals' erythrocyte DNA. Zhao et al. (2020) reported MWCNT accumulation in different organs of tadpoles belonging to species $X$. tropicalis increased their lethality rate and changed their heart rate. Thus, it is imperative carrying out further studies to assess how CNTs can have impact on the anurofauna and ecotoxicological effects of CNFs. These complementary investigations are essential, since amphibians are organisms sensitive to changes in their habitats (Roy, 2002; Wagner et al., 2014; Rohman et al., 2020), and are included in the list of animals presenting significant population decline in recent years (Green et al., 2020).

Accordingly, we evaluated the likely toxicological effects of CNFs on tadpoles belonging to neotropical species Physalaemus cuvieri (Anura, Leptodactylidae). This species is exclusively distributed in South America and is typical of open biomes, such as Cerrado, Caatinga, Chaco and Llanos (Mijares et al., 2011; De-Oliveira-Miranda et al., 2019). Although the species is currently categorized as of "little concern" by the International Union for Conservation of Nature (stable, least concern, version 2020-3) (IUCN, 2020), its wide geographical distribution and presumed large populations, are features turning them into interesting model systems, since they can inhabit freshwater environments subjected to different pollution types, including CNFs. From different biomarkers, We herein aimed at testing the hypothesis that short exposure to CNFs (at environmentally relevant concentrations) induces changes in the nutritional status, metabolic changes altering REDOX homeostasis into oxidative stress, and cytotoxic and neurotoxic changes in 
113 these animals. To the best of our knowledge, this is the first report on the biological impact of CNFs

114 on a specific amphibian species. Therefore, this study has broadened our understanding about

115 ecological risks associated with water pollution by these nanomaterials, as well as motivated further

116 investigations on the impact of CNs on amphibians' health and on the dynamics of their natural

117 populations.

\section{2. MATERIALS AND METHODS}

\subsection{Carbon nanofibers}

We used pyrolytically stripped CNFs (i.e., polyaromatic hydrocarbons removed from fibers' surface) provided by Sigma-Aldrich (San Luis, Missouri, USA) - their detailed chemical featuring was presented by Gomes et al. (2021). These pollutants are a mix of different sized and shaped CNFs [from 60 to $100 \mathrm{~nm}$ (mean: $86.85 \pm 1.80 \mathrm{~nm}$ )], including the ones with open and clearly curved tips (Figure 1). According to the manufacturer, and as seen in the photoelectric micrographs taken during the transmission electron microscopy analysis, the assessed CNFs have different metallic particles ( $\mathrm{Ca}, \mathrm{Si}, \mathrm{S}, \mathrm{Na}, \mathrm{Mg}$ and $\mathrm{Fe}$ ), used as catalysts (Figure 1).
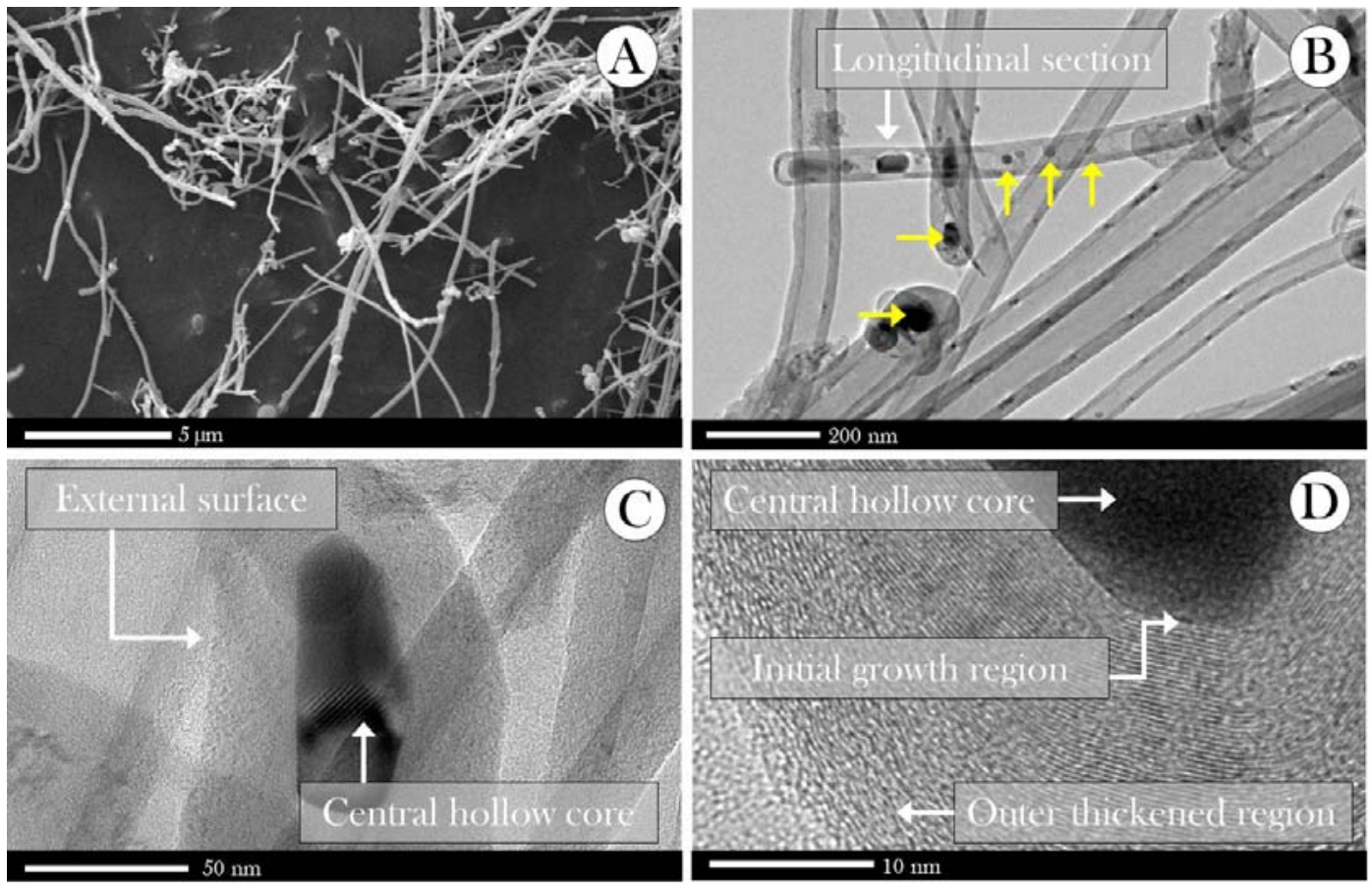

Figure 1. (A) Scanning electron microscopy images and (B-D) transmission electron microscopy images of a CNF film, at different magnifications. Yellow arrows point out the presence of metallic particles inside CNFs, or around their surface, as shown in (D).

\subsection{Model system and experimental design}

We used tadpoles belonging to species P. cuvieri (Anura, Leptodactylidae) as model system 
131 et al., 2019), stability and population abundance in the occupied areas (Frost, 2017), good

132 adaptability to laboratory environment, early biological response to changes in its environment, and

133 use in recent (eco) toxicological studies justify their choice as model in our study (Herek et al.,

134 2020; Araújo et al., 2020ab; Rutkoski et al., 2020). All tadpoles used in the experiment came from

135 an ovigerous mass with approximately 1,500 eggs, based on Pupin et al. (2010). The ovigerous mass

136 was collected in a lentic environment (Urutaí, GO, Brazil) surrounded by native Cerrado biome,

137 under license n. 73339-1 - issued by the Brazilian Biodiversity Authorization and Information

138 System (SISBIO/MMA/ICMBio).

139 Eggs were kept in aquarium $(40.1 \times 45.3 \times 63.5 \mathrm{~cm})$ filled with $80 \mathrm{~L}$ of naturally 140 dechlorinated water (for at least $24 \mathrm{~h}$ ), under controlled $12 \mathrm{~h}$ light-dark photoperiod and 141 temperature $\left(26^{\circ} \mathrm{C} \pm 1{ }^{\circ} \mathrm{C}\right.$ - similar to that of the natural environment) conditions, and constant 142 aeration (by air compressors) from the time they were taken to the laboratory. Animals were fed 143 once a day (ad libitum) with commercial fish food (formula: 45\% crude protein, 14\% ether extract, $1445 \%$ crude fiber, $14 \%$ mineral matter and $87 \%$ dry matter). Tadpoles remained under the 145 aforementioned conditions until they reached stage $27 \mathrm{G}$ (body biomass: $70 \mathrm{mg} \pm 4.1 \mathrm{mg}$; and total 146 length: $20.1 \mathrm{~mm} \pm 0.7 \mathrm{~mm}$ - mean \pm SEM)., after egg hatching, based on Gosner (1960). The 147 healthy tadpoles (i.e., the ones presenting normal swimming movements and no morphological 148 deformities or apparent lesions) were divided into three experimental groups ( $\mathrm{n}=195$ 149 tadpoles/each - 13 replicates composed of 15 animals/each). The control group (C) was composed of 150 tadpoles kept in dechlorinate tap water (CNFs free) and groups CNF-I and CNF-II comprised 151 animals exposed to water added with CNFs at concentrations of 1 and $10 \mathrm{mg} / \mathrm{L}$, respectively (see 152 below).

\subsection{Exposure conditions and CNF concentrations} dechlorinated water where CNFs were diluted in. Exposure time was set at $48 \mathrm{~h}$ (static system) to simulate ephemeral exposure. Animals' food was kept during exposure - commercial feed was offered once a day. Concentrations of the tested CNFs were defined based on aquatic CNT concentrations, due to lack of information about environmental concentrations recorded for CNFs. Therefore, previous studies evaluating CNTs' toxicity in different experimental models based on concentrations ranging from 0.1 to $100 \mathrm{mg} / \mathrm{L}$ were taken as basis to select CNF concentrations used in the current research (Mouchet et al., 2007; Mouchet et al., 2009; Mouchet et al., 2010; Mouchet et al., 2011; Bourdiol et al., 2013; Saria et al., 2014; Verneuil et al., 2015; Zhao et al., 2020; Tavabe et al., 
aquatic environments and the experimental design proposed by Tavabe et al. (2020). The aforementioned authors observed concentration up to $20 \mathrm{mg} / \mathrm{L}$ of these materials, and it proved the significant changes in it $(\mathrm{ng} / \mathrm{L}$ to $\mathrm{mg} / \mathrm{L})$. Concentrations tested in the current study were environmentally relevant, and it takes the present experimental design closer to realistic CNFpollution conditions. The herein adopted concentrations represented both optimistic (less pollution; $1 \mathrm{mg} / \mathrm{L}$ ) and pessimistic (higher pollution; $10 \mathrm{mg} / \mathrm{L}$ ) conditions.

\subsection{Toxicity biomarkers}

\subsubsection{Biochemical assessments}

\subsubsection{Sample preparation}

Samples were prepared based on Guimarães et al. (2021), with modifications, to evaluate the biochemical parameters. In total, 144 tadpoles were used per experimental group $(\mathrm{n}=12$ samples, composed of a pool of 12 animals/each). These animals were weighed, macerated in $1 \mathrm{~mL}$ of phosphate buffered saline (PBS) solution and centrifuged at $13,000 \mathrm{rpm}$, for $5 \mathrm{~min}\left(\mathrm{at} 4^{\circ} \mathrm{C}\right)$. The supernatant was separated into aliquots to be used in different biochemical evaluations. Whole bodies were used due to technical limitations in isolating certain organs from small animals. Unlike assessments in adult specimens, organ-specific biochemical assessment carried out in tadpoles require highly accurate dissection due to their small sized-bodies, which makes it difficult processing large numbers of samples under time constraint (Khan et al. 2015). Organ "contamination" by organic matter and/or by other particles consumed by tadpoles can be a bias for the biochemical analysis applied to organs during dissection time (Lusher et al. 2017; Guimarães et al., 2021).

\subsubsection{Nutritional status}

Different pollutants can affect the nutritional status of tadpoles (Bharatraj \& Yathapu, 2018); therefore, we evaluated total soluble carbohydrate, total protein, and triglyceride concentrations in different tissues of the exposed animals. Total soluble carbohydrate levels were determined through the Dubois method (Dubois et al., 1956) - detailed by Estrela et al. (2021). Protein level was determined in commercial kit (Bioténica Ind. Com. LTD, Varginha, MG, Brazil. CAS number: 10.009.00), based on biuret reaction (Gornall et al., 1949; Henry et al., 1957). Triglyceride levels were evaluated based on Bucolo \& Davis (1973) by using a commercial kit (Bioténica Ind. Com. LTD, Varginha, MG, Brazil. CAS number: 10.010.00).

\subsubsection{REDOX state}




\subsection{Oxidative stress biomarkers}

Likely oxidative stress increase was assessed based on indirect nitric oxide (NO) determination, REDOX regulated processes through nitrite measurement (Soneja et al. 2005), thiobarbituric acid reactive species (TBARS) [predictive of lipid peroxidation (De-Leon \& Borges, 2020)], reactive oxygen species (ROS) production and on hydrogen peroxide $\left(\mathrm{H}_{2} \mathrm{O}_{2}\right)$ - which plays essential role in responses to oxidative stress, in different cell types (Sies, 2020; Sies et al., 2020). The Griess colorimetric reaction [based on Bryan et al., (2007)] was used to measure nitrite concentrations. TBARS levels were determined based on procedures described by Ohkawa et al. (1979) and modified by Sachett et al. (2020). $\mathrm{H}_{2} \mathrm{O}_{2}$ and ROS production was assessed based on the methodological procedures proposed by Elnemma et al. (2004) and Maharajan et al. (2018), respectively.

\subsection{Antioxidant response biomarkers}

The activation or suppression of antioxidant activity in animals exposed to different CNF concentrations was evaluated by determining catalase and superoxide dismutase (SOD) activity. These enzymes are considered first-line antioxidants important for defense strategies against oxidative stress (Ighodaro \& Akinloye, 2018). Catalase activity was assessed based on Sinha et al. (1972) [see details in Montalvão et al. (2021)] and SOD was determined according to the method originally described by Del-Maestro \& McDonald (1985) and adapted by Estrela et al. (2021).

\subsubsection{Cytotoxicity}

Blood samples were collected to assess cytotoxic effects induced by CNFs through erythrocytic apoptosis or necrosis. Procedures like those described by Singla \& Dhawan (2013) and García-Rodríguez et al. (2013) were herein adopted. Briefly, 0.5-1.0 $\mu \mathrm{L}$ of blood from two animals in each group ( $\mathrm{n}=16$ por grupo) was mixed to $200 \mu \mathrm{L}$ of PBS. Subsequently, $50 \mu \mathrm{L}$ of acridine orange dye solution (AO) and $50 \mu \mathrm{L}$ of ethidium bromide (EB) solution (both at $1 \mu \mathrm{g} / \mathrm{mL}$ ) were added to the mix, which was incubated at room temperature, for $5 \mathrm{~min}$. Samples were then centrifuged (at 13,000 rpm and $4^{\circ} \mathrm{C}$, for $\left.5 \mathrm{~min}\right)$. The pellet was resuspended, placed on slide and covered with a glass cover slip after the supernatant was discarded. A barrier filter for immediate evaluation under fluorescence microscope (BEL Engineering®, model FLUO3 - excitation 510-560 nm) was used in the experiment. The total number of 100 cells from each slide was scored for apoptosis extent quantification. Living cells were green, apoptotic cells were orange and presented fragmented nuclei, and necrotic cells were red (Kasibhatla et al., 2006; Singla \& Dhawan, 2013). The rate of each cell type, in each animal, was calculated. 


\subsubsection{Neurotoxicity}

The induction of likely neurotoxic effect caused by CNFs was evaluated by determining acetylcholinesterase (AChE) activity based on the method by Ellman et al. (1961) and the activity of butyrylcholinesterase (BChE) - also known as serum cholinesterase or pseudocholinesterase based on Silva et al. (2020). We also evaluated whether CNFs could change the viability of neuromats living on tadpoles' surface (Russell, 1976) - this feature has been considered a good ecotoxicological biomarker (Guimarães et al., 2021). Accordingly, 10 living tadpoles from each group were exposed (for $15 \mathrm{~min}$ ) to water reconstituted with 4- (4-Diethylaminostyryl) -1methylpyridinium iodide (4-Di-2-ASP) at $5 \mathrm{mM}$, similar to procedures adopted by Krupa et al. (2020) and Guimarães et al. (2021). Subsequently, animals were anesthetized (on ice) and taken to fluorescence microscope (BEL Engineering ${ }^{\circ}$, model FLUO3 - excitation 510-560 nm) to have images of their heads and tails captured. The number of neuromats was manually determined; neuromats located on the sides of the tadpoles were excluded because they were out of focus or absent, due to their position in the microscope. We also excluded the lower part of their head and their back-posterior region, which overall had expressive amounts of non-specific coloring. Neuromats on the head and tail sides were quantified, as shown in Figure 2.

\subsection{CNF accumulation}

CNF accumulation was estimated by determining total organic carbon (TOC) concentrations by taking into consideration the specific quantification of $\mathrm{CNs}$ in environmental and biological samples. This process is a huge challenge, given the lack of accessible standard methods to quantify these nanomaterials (Wang et al., 2013; Chang et al., 2014; Bourdiol et al., 2015; Petersen et al., 2016). We herein adopted the Walkley-Black method used by Schwab et al. (2011) and Gomes et al. (2021); this method is based on using dichromate as oxidizer in acid medium (Walkley \& Black, 1934). Detailed methodological procedures can be observed in a previous study carried out by our research team (Gomes et al., 2021). Results were expressed in "g of TOC/kg of body biomass" ( $n=16 /$ group, 8 samples composed of a pool of 2 animals/each). 

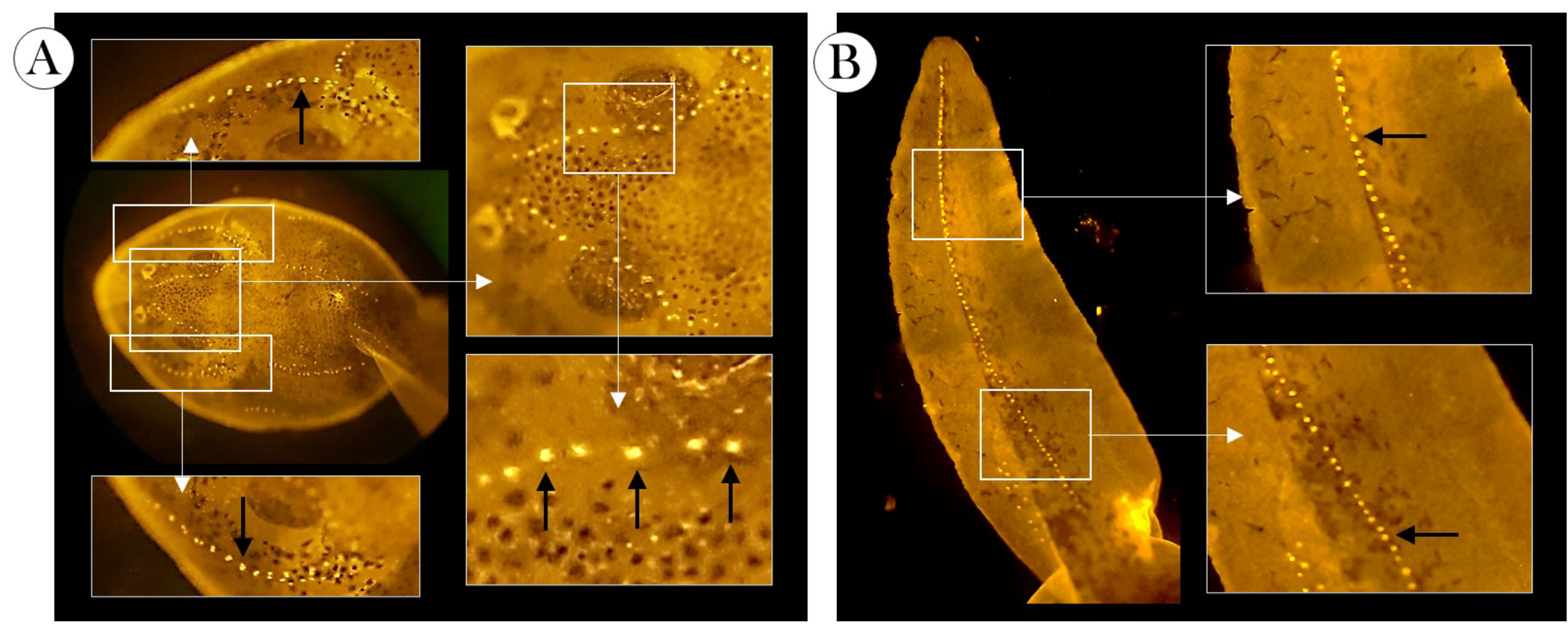

Figure 2. Representative images of the (A) head and (B) tail regions of P. cuvieri tadpoles, whose number of superficial neuromats were counted. 


\subsection{Visual assessment}

Nine tadpoles randomly selected from each group were euthanized on ice and incubated in acridine orange dye $(\mathrm{AO})$ and ethidium bromide (EB) solution (both at $1 \mu \mathrm{g} / \mathrm{mL}$ ), at room temperature for $10 \mathrm{~min}$, in addition to CNF accumulation estimates. Such procedure allowed better differentiating different regions of animal's body displaying accumulated CNFs. Their animals were captured in fluorescence microscope (BEL Engineering®, model FLUO3 - excitation 510-560 nm) for further qualitative evaluation.

\subsection{Statistical analysis}

GraphPad Prism Software Version 8.0 (San Diego, CA, USA) was used to the statistical analyses. Initially, data were checked for normality and homogeneity variance deviations before the analysis. Normality data were assessed through Shapiro-Wilks test, and variance homogeneity was assessed through Bartlette's test. Multiple comparisons were performed by applying one-way ANOVA and Tukey's post-hoc analysis to non-parametric data or Kruskal-Wallis test, Dunn's post-hoc test to non-parametric data. Significance levels were set at Type I error (p) values lower than $0.05,0.01$ or 0.001 .

\section{RESULTS}

By assuming the possible interference of CNFs in tadpoles' energy metabolism, we evaluated the concentration of different macromolecules. Both concentrations recorded for the tested CNFs have significantly reduced total soluble carbohydrate and total protein levels in these animals, except for triglyceride levels, whose reduction was only observed in animals in the CNF-II group (Figure 3) - with no concentration-response effect. Based on our data, CNFs induced nitrite production increase in animals belonging to group CNF-I (Figure 4A), as well as in $\mathrm{H}_{2} \mathrm{O}_{2}$ and ROS production in both groups exposed to nanomaterials (Figure 4B-C, respectively), and TBARS production in animals kept in water added with $10 \mathrm{mg} / \mathrm{L}$ of CNFs (Figure 4D). 


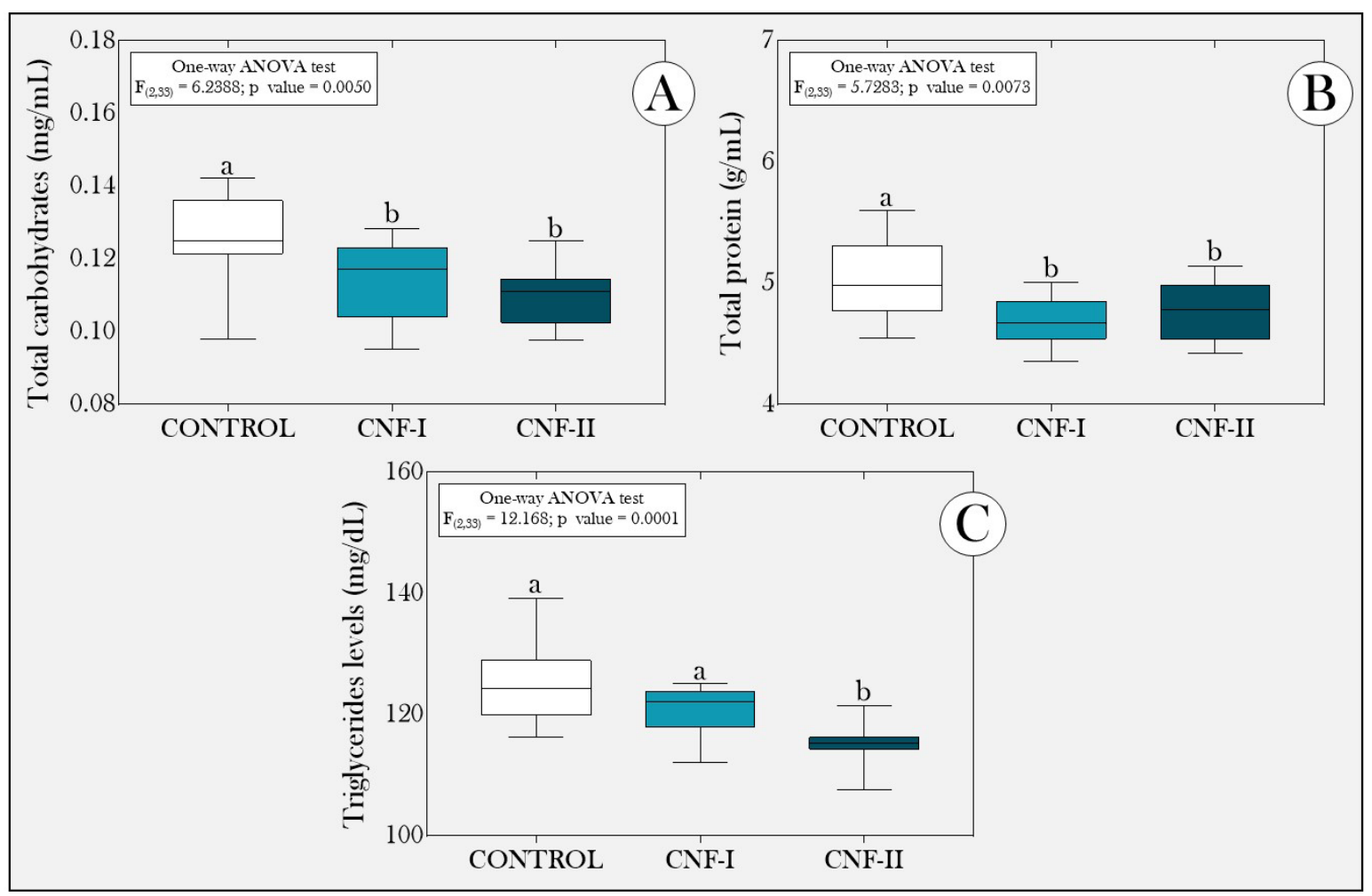

Figure 3. Boxplot of (A) total soluble carbohydrate, (B) total protein and (C) triglycerides concentration in P. cuvieri tadpoles exposed, or not, to different CNF concentrations. Summaries of statistical analyses are shown in the upper left corner of the figures. Different lowercase letters indicate significant differences between experimental groups. CONTROL: group of tadpoles not exposed to CNFs. CNF-I and CNF-II groups: tadpoles exposed to carbon nanofibers at concentrations of 1 and $10 \mathrm{mg} / \mathrm{L}$, respectively. $\mathrm{n}=144$ tadpoles/group, 12 samples/group composed of a pool of 12 animals/each. 


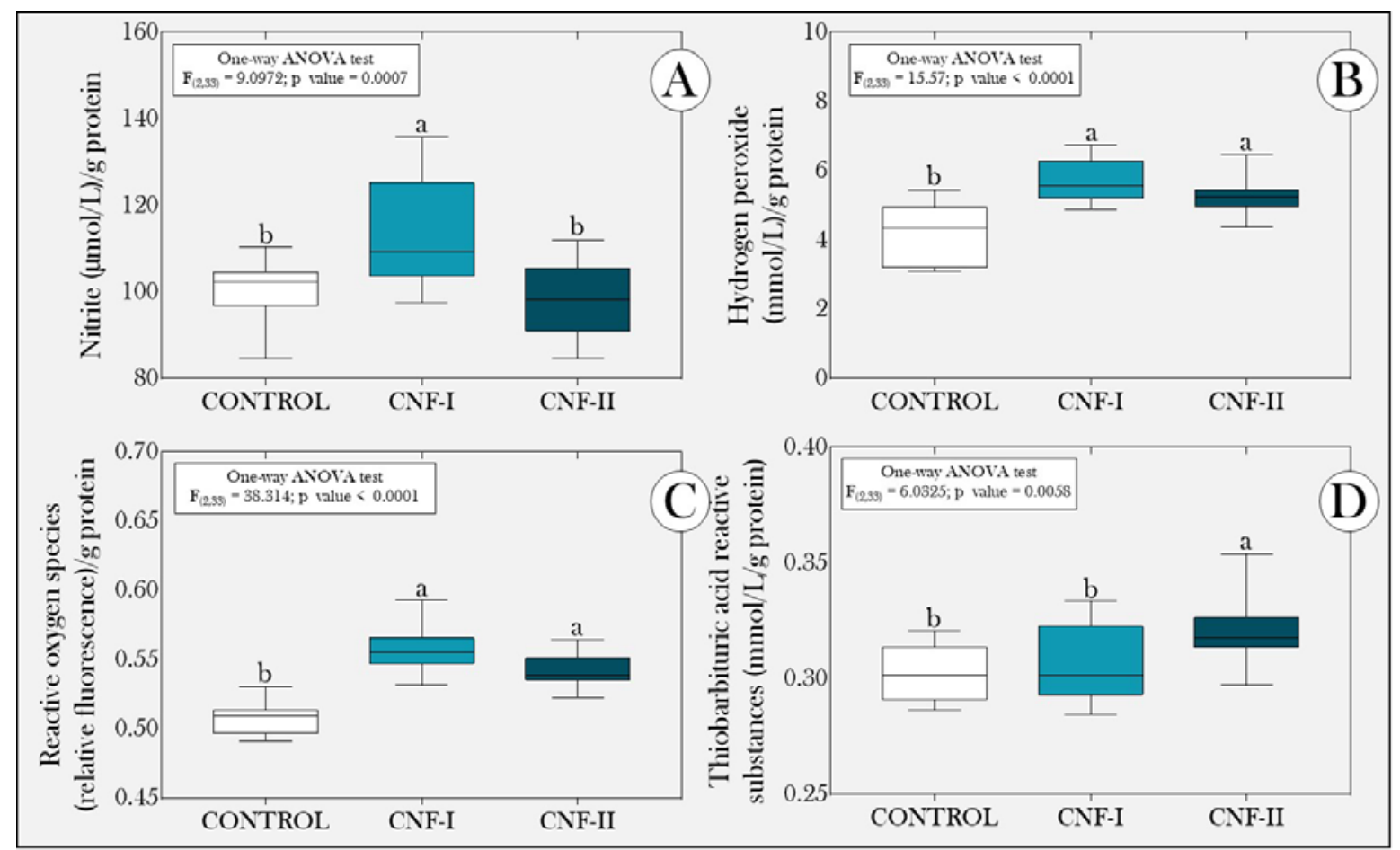

Figure 4. Boxplot of (A) nitrite, (B) hydrogen peroxide, (C) reactive oxygen species (ROS) and

(D) thiobarbituric acid reactive substances concentrations in P. cuvieri tadpoles exposed, or not, to different CNF concentrations. Summaries of statistical analyses are shown in the upper left corner of the figures. Different lowercase letters indicate significant differences between experimental groups. CONTROL group: tadpoles not exposed to CNFs. CNF-I and CNF-II groups: tadpoles exposed to carbon nanofibers at concentrations of 1 and $10 \mathrm{mg} / \mathrm{L}$, respectively ( $n=144$ tadpoles/group, 12 samples/group composed of a pool of 12 animals/each).

We observed significant increase in SOD and catalase levels in animals exposed to CNFs,

294 but no concentration-response effect (Figure 5A-B, respectively). SOD levels were positively and significantly correlated to $\mathrm{H}_{2} \mathrm{O}_{2}$, ROS and TBARS levels (Table 1). Catalase concentrations were correlated to $\mathrm{H}_{2} \mathrm{O}_{2}$ and ROS production (Table 1). 


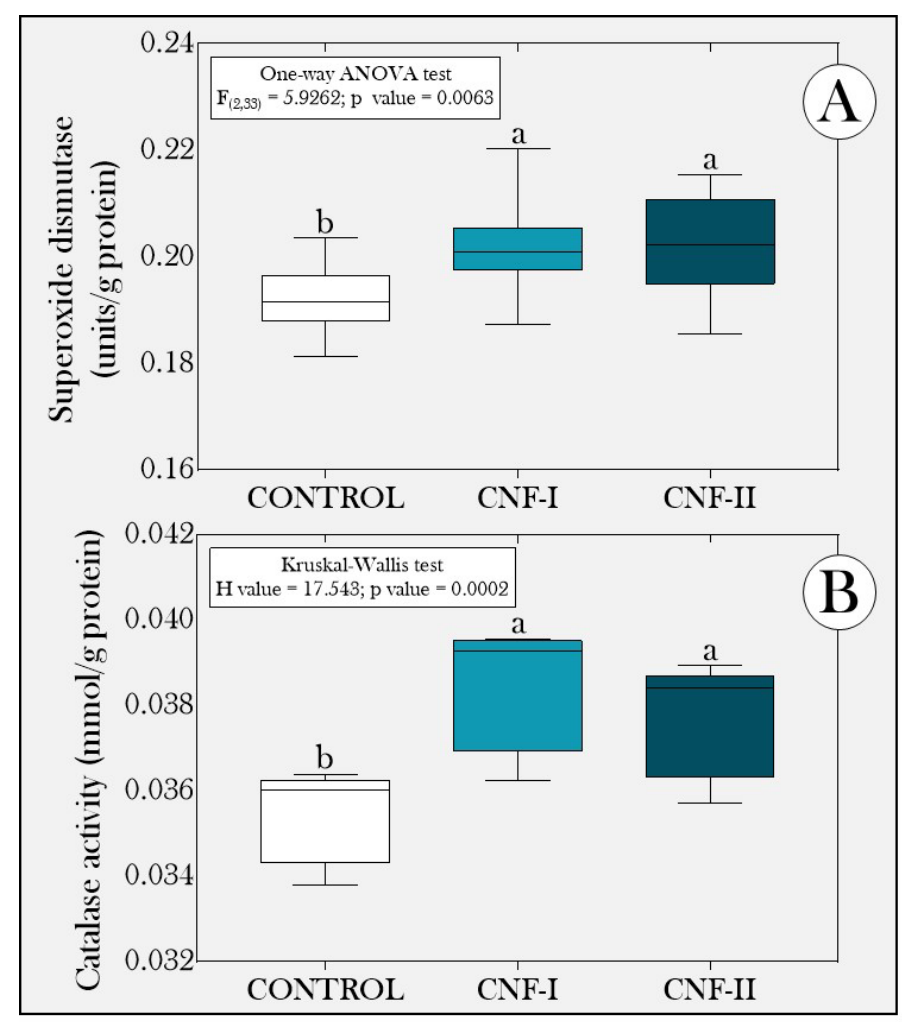

Figure 5. Boxplot of (A) superoxide and (B) dismutase concentration in tadpoles belonging to species P. cuvieri exposed, or not, to different CNF concentrations. Summaries of statistical analyses are shown in the upper left corner of the figures. Different lowercase letters indicate significant differences between experimental groups. CONTROL group: tadpoles not exposed to CNFs. CNF-I and CNF-II groups: tadpoles exposed to carbon nanofibers at concentrations of 1 and $10 \mathrm{mg} / \mathrm{L}$, respectively ( $\mathrm{n}=144$ tadpoles/group, 12 samples/group composed of a pool of 12 animals/each).

Based on our data, there was cytotoxic effect induced by CNFs on tadpoles' erythrocytes. Figure 6 depicts that the groups exposed to nanomaterials recorded lower rates of viable erythrocytes and, consequently, higher rates of apoptotic and necrotic cells than animals in the control group. The rate of viable cells was negatively and significantly correlated to ROS and TBARS concentrations (Table 1). According to the neurotoxic evaluation, there was AChE and BChE increase in animals exposed to nanomaterials, and this finding suggests the stimulatory effect induced by CNFs on tadpoles' cholinergic system (Figure 7A-B, respectively). On the other hand, tadpoles exposed to CNFs showed smaller number of superficial neuromats in their heads (Figure 8A) and a larger amount of them in their tail (Figure 8B), but no concentration-response effect. However, the total number of neuromats (head + tail) did not differ between experimental groups (Figure 8C). 
Table 1. Summary of correlation analyses carried out between different biochemical biomarkers.

\begin{tabular}{|c|c|c|}
\hline Correlated biomarkers & Spearman $r$ & $P$ value \\
\hline $\mathrm{SOD}$ vs. $\mathrm{H}_{2} \mathrm{O}_{2}$ & 0.4152 & 0.0118 \\
\hline SOD vs. ROS & 0.5806 & 0.0002 \\
\hline SOD vs. TBARS & 0.5477 & 0.0005 \\
\hline CAT vs. ROS & 0.4929 & 0.0023 \\
\hline CAT vs. $\mathrm{H}_{2} \mathrm{O}_{2}$ & 0.3393 & 0.0429 \\
\hline VER vs. ROS & -0.5270 & 0.0080 \\
\hline VER vs. TBARS & -0.4920 & 0.0150 \\
\hline TBARS vs. AChE & 0.3510 & 0.0313 \\
\hline TBARS vs. BChE & 0.3710 & 0.0280 \\
\hline $\mathrm{H}_{2} \mathrm{O}_{2}$ vs. $\mathrm{AChE}$ & 0.5690 & 0.0002 \\
\hline $\mathrm{H}_{2} \mathrm{O}_{2}$ vs. $\mathrm{BChE}$ & 0.3840 & 0.0223 \\
\hline ROS vs. AChE & 0.6270 & 0.0004 \\
\hline ROS vs. BChE & 0.5280 & 0.0010 \\
\hline TOC vs. ROS & 0.5245 & 0.0029 \\
\hline TOC vs. TBARS & 0.3911 & 0.0312 \\
\hline TOC vs. SOD & 0.4691 & 0.0136 \\
\hline TOC vs. CAT & 0.4269 & 0.0264 \\
\hline TOC vs. APOP & 0.4462 & 0.0173 \\
\hline TOC vc. NECR & 0.4750 & 0.0106 \\
\hline TOC vs. VER & 0.4686 & 0.0119 \\
\hline TOC vs. NH & -0.4744 & 0.0081 \\
\hline TOC vs. AChE & 0.5777 & 0.0008 \\
\hline TOC vs. BChE & 0.5707 & 0.0012 \\
\hline
\end{tabular}

SOD: superoxide dismutase; $\mathrm{H}_{2} \mathrm{O}_{2}$ : hydrogen peroxide; TBARS: thiobarbituric acid reactive

319 substances; AChE: acetylcholinesterase activity; BChE: butyrylcholinesterase activity; APOP: rate 320 of apoptotic erythrocytes; NECR: rate of necrotic erythrocytes; VER: rate of viable erythrocytes; $\mathrm{NH}$ : number of neuromats in the tadpoles' heads; TCO: total organic carbon. 


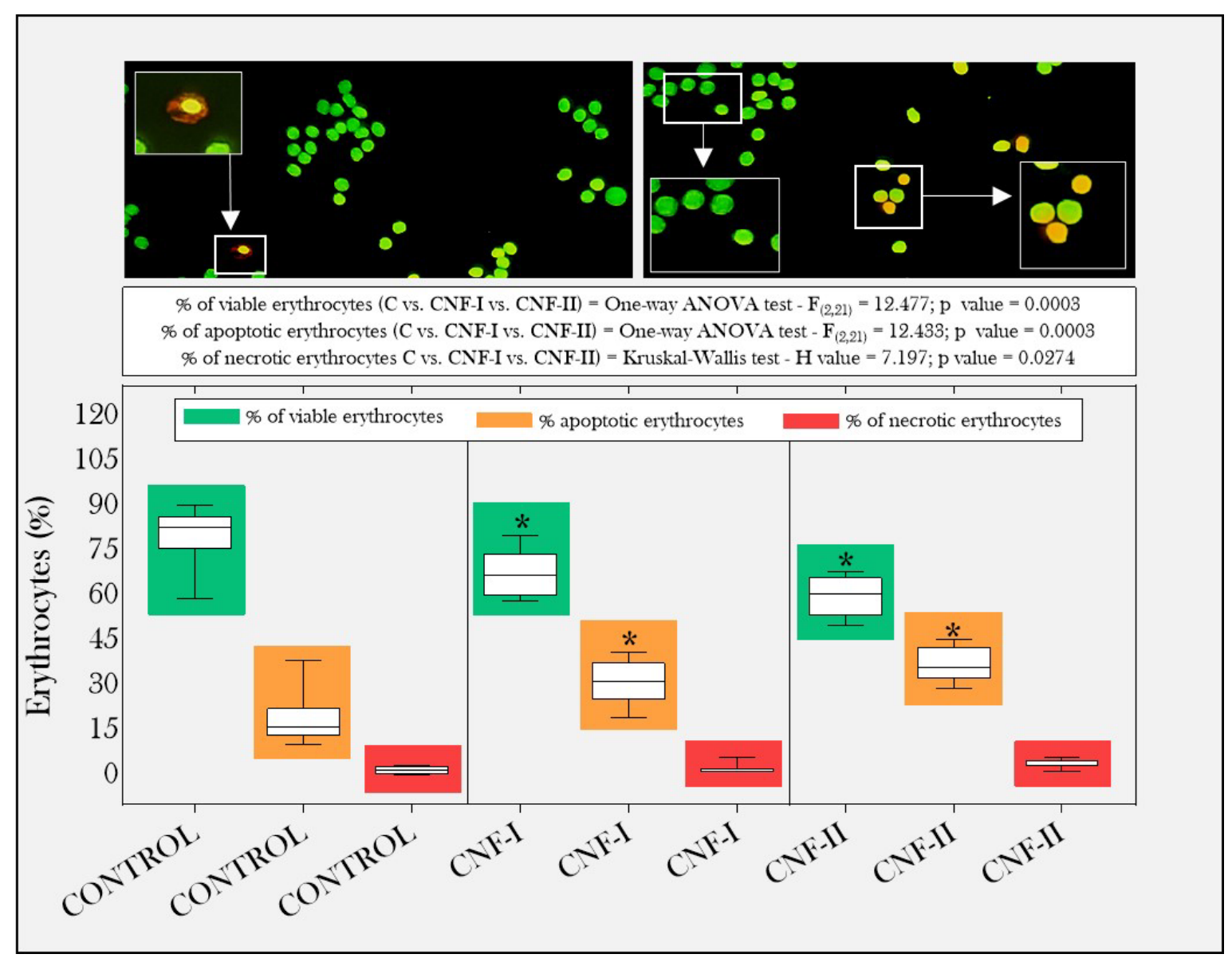

Figure 6. Boxplot of viable (green), apoptotic (orange) and necrotic (red) erythrocyte rates in $P$. cuvieri tadpoles exposed, or not, to different CNF concentrations. Fluorescence images representative of acridine orange and ethidium bromide staining are presented above the boxplot. Summaries of statistical analyses are shown in the upper left corner of the figures. Asterisks indicate differences between the respective cell types from each group exposed to CNFs and from the control group. CONTROL group: tadpoles not exposed to CNFs. CNF-I and CNF-II groups: tadpoles exposed to carbon nanofibers at concentrations of 1 and $10 \mathrm{mg} / \mathrm{L}$, respectively $(\mathrm{n}=16$ tadpoles/group, 8 samples, composed of a pool of two animals/each). 


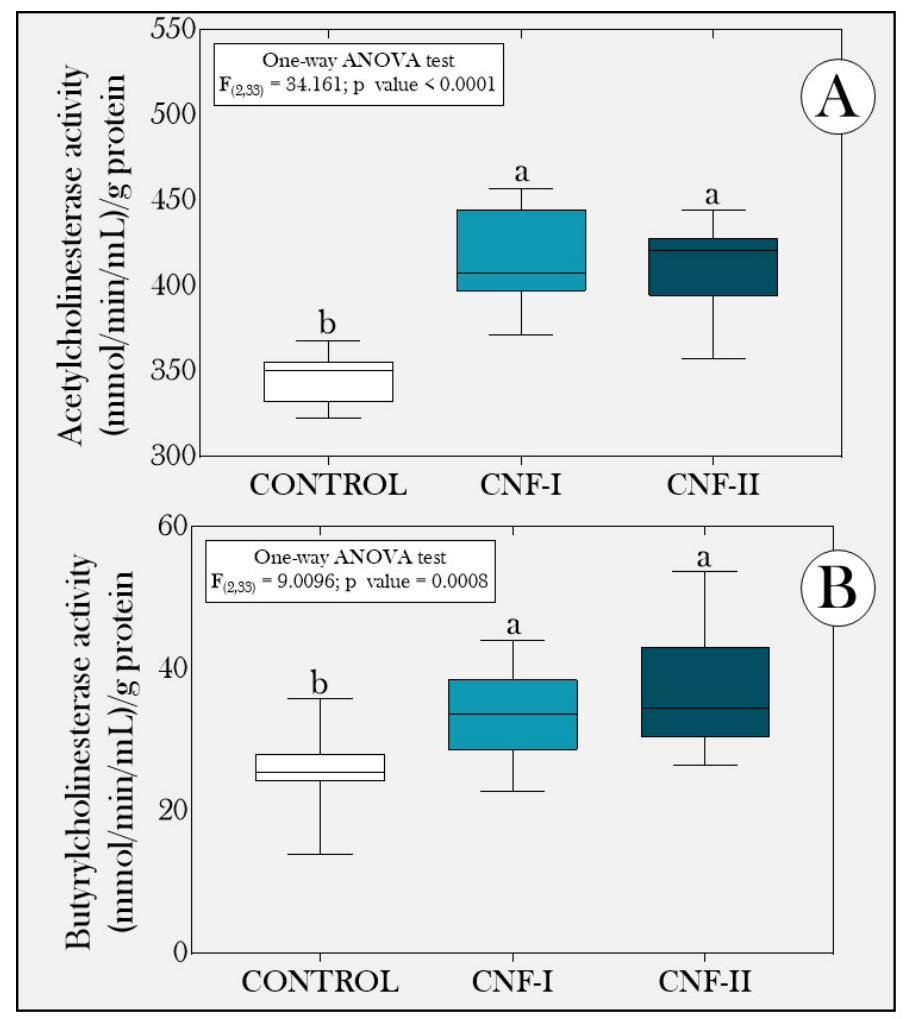

Figure 7. Boxplot of (A) acetylcholinesterase and (B) butyrylcholinesterase activity in P. cuvieri tadpoles exposed, or not, to different CNF concentrations. Summaries of statistical analyses are shown in the upper left corner of the figures. Different lowercase letters indicate significant differences between experimental groups. CONTROL group: tadpoles not exposed to CNFs. CNF-I and CNF-II groups: tadpoles exposed to carbon nanofibers at concentrations of 1 and 10 mg/L, respectively $(\mathrm{n}=144$ tadpoles/group, 12 samples/group composed of a pool of 12 animals/each). 


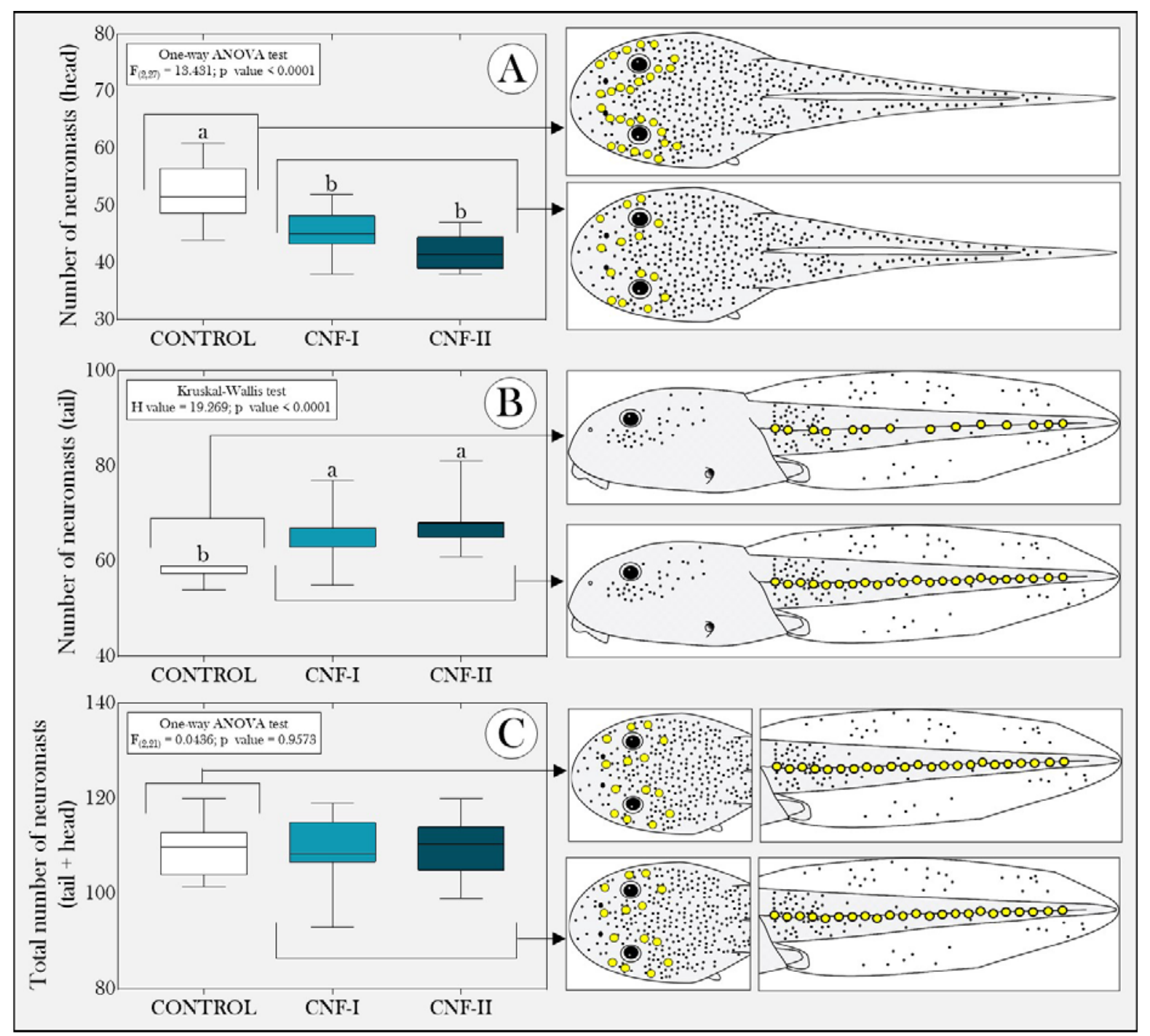

Figure 8. Boxplot of number of superficial neuromats in the (A) head and (B) tail of tadpoles, and the total number $(\mathrm{C})$ of $P$. cuvieri tadpoles exposed, or not, to different CNF concentrations. Summaries of statistical analyses are shown in the upper left corner of the figures. Different lowercase letters indicate significant differences between experimental groups. CONTROL group: tadpoles not exposed to CNFs. CNF-I and CNF-II groups: tadpoles exposed to carbon nanofibers at concentrations of 1 and $10 \mathrm{mg} / \mathrm{L}$, respectively ( $\mathrm{n}=10$ tadpoles/group).

Finally, we observed the accumulation of nanomaterials in tadpoles belonging to groups CNF-I and CNF-II - this finding was inferred based on TOC concentrations (Figure 10A) and on animals' visual evaluation (Figure 10B-C) - with concentration-response effect. We noticed significant CNF accumulation in animals' gastrointestinal tract; it prevailed in the ones exposed to the highest CNF concentration $(10 \mathrm{mg} / \mathrm{L})$. These data have confirmed that CNFs were ingested by tadpoles; the statistical analyses have shown significant correlation among the accumulation of 
334 these nanomaterials, different biomarkers predictive of oxidative stress (ROS and TBARS),

335 antioxidant activity (SOD and CAT), as well as cytotoxic (viable, apoptotic, and necrotic

336 erythrocytes) and neurotoxic effect (number of neuroblasts in tadpoles, as well as AChE and BChE

337 activity in these models) (Table 1).

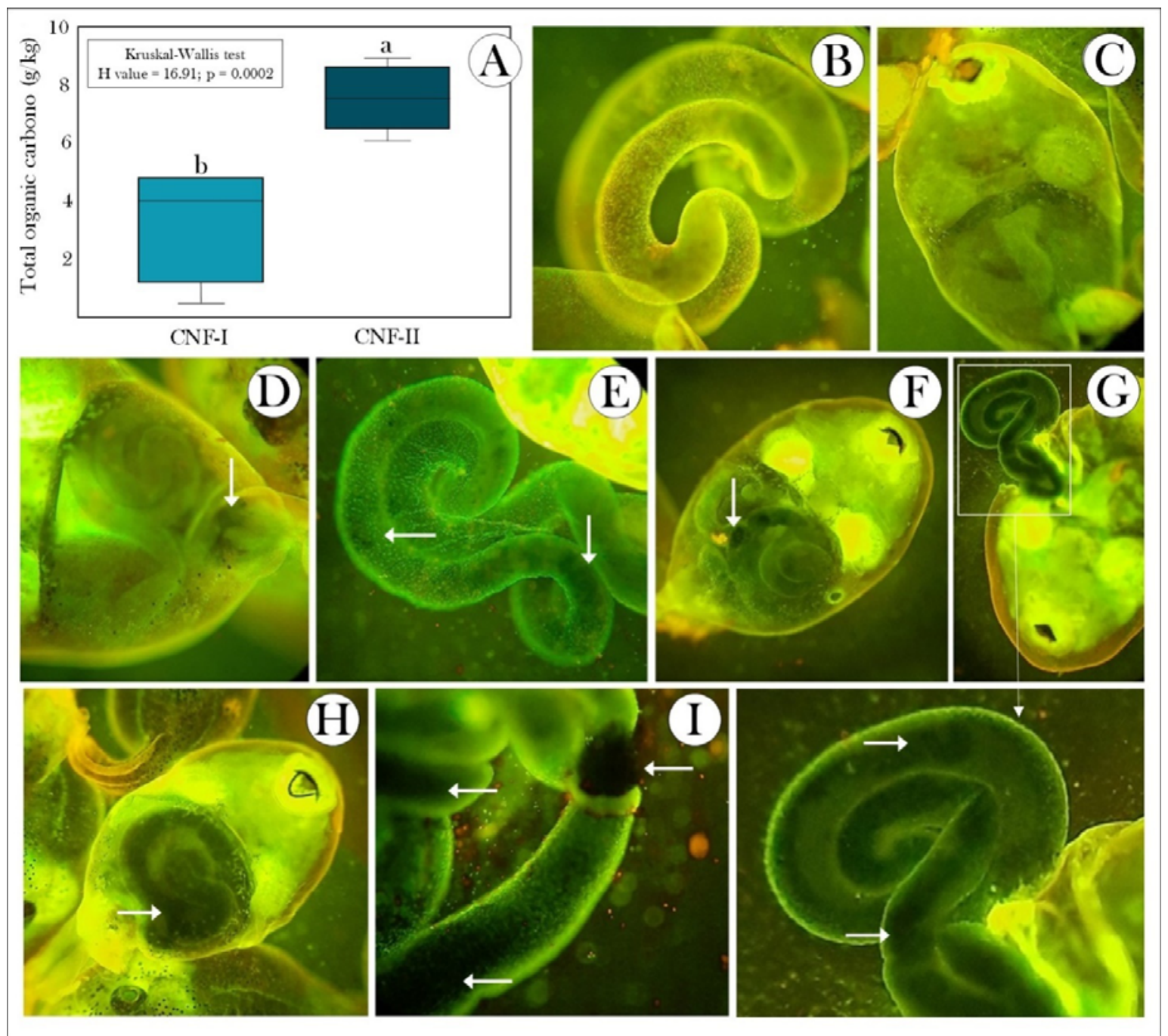

Figure 10. Boxplot of (A) total organic carbon concentration and (B-I) representative images of P. cuvieri tadpoles exposed, or not, to different CNF concentrations. "A", the summary of the statistical analysis is shown in the upper left corner of the figure. Different lowercase letters indicate significant differences between experimental groups. Background TOC concentrations in tadpoles in the control group were detected and subtracted from that of CNFs-exposed samples. (B-C): representative images of P. cuvieri tadpoles not exposed to CNFs, (D-F) images of animals exposed to the lowest (1 mg/L) and (G-I) highest concentrations (10 mg / L) of the pollutant. CNF-I and CNF-II groups: tadpoles exposed to carbon nanofibers at concentrations of 1 and 10 mg/L, respectively. Representative images of $n=9$ tadpoles/group. “A”, data about $n=16 /$ group, 
8 samples, composed of a pool of two animals/each. Arrows indicate CNF accumulation in animals.

\section{DISCUSSION}

Identifying and featuring the effect of organisms' exposure to different pollutants and contaminants are essential procedures to assess ecotoxicological risks associated with environmental pollution (Eason \& O'Halloran, 2002; O'Halloran, 2006; Rand, 2020). Furthermore, the aforementioned studies can generate important subsidies for further remediation/mitigation measures to prevent the occurrence of lethal effects on the herein assessed animals (Madear et al., 2020; Wang et al., 2020). Accordingly, our study was the first to show how CNFs can have impact on the health of anurofauna. This finding reinforces the toxicological potential of these nanomaterials inferred through tests carried out in vitro and in vivo with organisms from other taxonomic groups (Magrez et al., 2006; Brown et al., 2007; Jensen et al., 2012; DeLorme et al., 2012; Jensen et al., 2012; Lee et al., 2015; Kalman et al., 2019; Warheit, 2019). triglyceride concentrations in P. cuvieri tadpoles exposed to CNFs (Figure 3) and to other types of pollutants (e.g.: atrazine: Dornelles \& Oliveira, 2014; glyphosate: Dornelles \& Oliveira, 2016; quinclorac: Dornelles \& Oliveira, 2014; basudin: Ezemonye \& Ilechie, 2007; naphthenic acids: Melvin et al., 2013; polycyclic aromatic hydrocarbons: Gendron et al., 1994, among others) has proven that CNFs can have impact on the energy metabolism of these models. Therefore, our results have suggested the direct or indirect activation of metabolic pathways related to glycogenolysis, proteolysis and lipolysis by CNFs. In this case, assumingly, the high energy consumption demanded by physiological processes of antioxidant defense, whose association was previously discussed (Strong et al., 2017) can explain the lower concentrations of the assessed macromolecules. Therefore, it is possible stating that CNF accumulation in animals' gastrointestinal system (Figure 9) was affected by nutrient absorption either by space occupation in the intestinal lumen [like reports involving microplastic consumption by tadpoles (Araújo et al., 2020a)] or by its negative effects on intestinal absorptive cells or on tadpoles' hepatic system. We could rule out the hypothesis that CNF accumulation in tadpoles' gastrointestinal tract itself can trigger physiological mechanisms capable of diminishing these models' food capture motivation, as also proposed by Araújo \& Malafaia (2020). The false satiety feeling of the animals can reduce carbohydrate, lipid, and tissue protein rates in tadpoles' bodies. In any case, nutritional deficits can have broader ecological consequences in tadpoles, regardless of the physiological mechanisms altered during 
exposure to CNFs, since the diverting energy from other processes, such as growth and development, to maintain physiological homeostasis, often has negative effect on these animals' health.

On the other hand, our data have evidenced CNFs' ability to induce oxidative stress increase, which was inferred based on ROS, $\mathrm{H}_{2} \mathrm{O}_{2}$ and TBARS concentrations (Figure 4) - SOD and catalase activation (Figure 5) was not enough to maintain homeostasis REDOX in tadpoles exposed to the tested nanomaterials. Although the literature about studies involving amphibians' exposure to any $\mathrm{CN}$ carried out in vivo is scarce, our data have corroborated results in reports by Sari et al. (2014). These authors reported that increased $\mathrm{H}_{2} \mathrm{O}_{2}$, glutathione reductase, SOD and catalase rates in tadpoles belonging to species Xenopus leavis were exposure-time (2, 4, 8, 12 and $24 \mathrm{~h})$ and MWCNT - (0.1, 1 and $10 \mathrm{mg} / \mathrm{L})$ dependent.

From the biochemical viewpoint, the most important enzymatic pathways for antioxidant defense against ROS are those involving SOD, since they convert the superoxide anion radical $\left(\mathrm{O}_{2}{ }^{-}\right)$ into $\mathrm{H}_{2} \mathrm{O}_{2}$, and catalase, which converts $\mathrm{H}_{2} \mathrm{O}_{2}$ into $\mathrm{H}_{2} \mathrm{O}$ molecules and $\mathrm{O}_{2}$ (Lee et al., 2018; Ransy et al., 2020; Damiano et al., 2020). Based on such an information, it is tempting to speculate that the increased oxidative stress observed in our study can be explained by different responses to CNFs. One possibility for this statement could be related to the negative effect of CNFs on catalases' molecular structure, because it decreases catalases' enzymatic efficiency or influences its affinity with the substrate. It is so because $\mathrm{H}_{2} \mathrm{O}_{2}$ molecules formed through SOD activity would not be neutralized by catalase, although its activity increases in animals exposed to CNFs. In this case, even greater increase would be necessary to balance SOD and catalase activity. However, assumingly, $\mathrm{H}_{2} \mathrm{O}_{2}$ is released as the product from other metabolic routes [see review by Hernandez et al. (2012)], catalyzed by enzymes, such as alcohol (Siebum et al., 2006; Ferreira et al., 2010; Turner, 2011), glucose (Zhou et al., 2010; Wang et al ., 2011), galactose (Siebum et al., 2006; Turner et al., 2011), lactate (Gao et al., 2011), glycolate (Das et al., 2010), cholesterol (Pollegioni et al., 2009; Saxena et al., 2011), L-amino acid (Schrittwieser et al., 2011), D-aminoacid (Pollegioni \& Molla, 2011) and monoamine oxidase (Buto et al., 1994; Edmondson et al., 2014). It is also plausible assuming that high ROS production in tadpoles in the CNF-I and CNF-II groups is associated with inflammasomes activation [intracellular multiprotein complexes activating caspases] by nanomaterials, whose reactive species formed in these systems are part of biochemical signaling reactions that can also activate inflammation through the production of several pro-inflammatory cytokines [see more details in Tschopp \& Schroder (2010)]. Increased TBARS, mainly in the CNF-II group (Figure 4), suggested lipoperoxidation oxidative stress induced by CNFs, whose changes in biological membranes can further intensify ROS production (Itri et al., 2014). 
Nevertheless, oxidative stress increase can cause different physiological consequences in organisms, such as increase in apoptotic and necrotic processes, as observed in our study (Figure 6).

These data are particularly interesting, since they corroborate other studies that have already shown the induction of cell death processes in different model systems exposed to CNFs (either in vitro or in vivo). This finding is indicative of nanomaterials activating apoptotic and necrotic pathways through different pathways (Bottini et al., 2006; Elgrabli et al., 2008; Ravichandran et al., 2009; Patlolla et al., 2010; Srivastava et al., 2011; Wang et al., 2012; Kim et al., 2014; Salehcheh et al., 2020). Furthermore, data in our study also suggested that the increased rate of apoptotic and necrotic erythrocytes may have happened because of damages to cell membranes caused by direct contact of these models with CNFs or by increased oxidative stress, which was inferred through different biomarkers (H2O2, ROS and TBARS). However, assumingly, CNFs induced increased expression of apoptosis genes (as demonstrated by Lee et al (2015)], mitochondrial membrane potential collapse (as suggested by Salehcheh et al. (2020)], DNA damage [ whose plausibility has already been demonstrated by Li et al. (2005) and Zhu et al. (2007)], and caspase activation [as suggested by Sohaebuddin et al. (2010)]. Shen et al. (2010) and Wang et al. (2012) have reported that $\mathrm{CNs}$ can cause, $\mathrm{Ca} 2+$ homeostasis imbalance and mitochondrial damage, as well as oxidative stress. These factors can be involved in MWCNTs-induced apoptosis and activate the production of the tumor necrosis factor by activating macrophages and monocytes, whose association with apoptosis and necrosis induction is well documented (Laster et al., 1988; Larrick \& Wright, 1990; Van-Herreweghe et al., 2010; Ni et al., 2016; Yao \& Cadwell, 2020; Liu \& Jiao, 2020).

Interestingly, we also noticed neurotoxic effect on tadpoles exposed to CNFs, and this finding was mainly inferred through increased $\mathrm{AChE}$ and $\mathrm{BChE}$ activity (Figure 7). BChE played important role in supporting $\mathrm{AChE}$ in cholinergic transmission regulation, mainly in the absence of AChE ( $\mathrm{Li}$ et al., 2000). However, these data are different from those reported in previous studies, such as those by Wang et al. (2007), Wang et al. (2009) and Cabral et al. (2013). Wang et al. (2009) and Cabral et al. (2013) reported that the anticholinesterase action of CNTs can be related to different action mechanisms, including the ones related to these nanomaterials' ability to adsorb AChE, to compete with $\mathrm{AChE}$ for its substrate and even to reduce the higher reaction speed $\left(\mathrm{V}_{\max }\right)$ of this enzyme due to the substrate's inability to reach the active site of the enzyme by immobilizing the nanomaterials. Wang et al. (2007) suggested that high BChE adsorption by the tested CNs promoted structural and functional changes that have led to significant reduction in enzyme activity.

Our data is following the study by Ibrahim et al. (2013), according to which, the direct effect of $\mathrm{CNs}$ on $\mathrm{AChE}$ activity did not cause significant change in the association and catalysis 
mechanism was observed. According to these authors, the catalytic constant increased as the Michaelis constant slightly decreased, and this finding is indicative of enzyme efficiency increase due to increased substrate affinity with the active site. The thermodynamic data of the enzyme's activation mechanisms showed no change in substrate interaction mechanism with the anionic binding site. Therefore, assumingly, similar mechanism could explain the $\mathrm{AChE}$ and $\mathrm{BChE}$ increase identified in tadpoles exposed to CNFs. Therefore, it is possible that the activation of these enzymes took place due to the indirect effects of CNFs rather than to the aforementioned process. Studies carried out in vitro have already shown that $\mathrm{H}_{2} \mathrm{O}_{2}$ strongly increased the AChE activity (Schallreuter et al., 2004; Garcimartín et al., 2017), and it reinforces the hypothesis that the high production of this reactive oxygen species has also stimulated the cholinesterase activity. It is plausible supposing interactions between CNFs and acetylcholine receptors, and that such interactions led to increased $\mathrm{AChE}$ and $\mathrm{BChE}$ synthesis for the decomposition of higher levels of this neurotransmitter. The hypothesis that the stimulatory effect of CNFs on the activity of these enzymes has been associated with positive regulation of the $\mathrm{AChE}$ and $\mathrm{BChE}$ genes due to the inhibitory effect of nanomaterials, but it needs to be tested in future studies.

We also observed that the exposure to CNFs seems to have affected populations of neuromats living in some regions of tadpoles' bodies, although in a different way. These cells are found in different amphibian species (Russel, 1976; Krupa et al., 2020) and make up a mechanosensory lateral line system with hair cells sensitive to movement, vibrations, and pressure gradients in the surrounding water (Lannoo, 1999). These cells are similar in morphology and function to hair cells in the auditory and vestibular system of other vertebrates (Mogdans, 2019; Roberts et al., 1988). Small movements in the water move the hair bundles of neuromast hair cells, and it mechanically opens the blocked ion channels (Harris et al., 1970; Sand et al., 1975). Hair cells (inside the neuromasts) depolarize and release neurotransmitters to the afferent neuronal terminals after water-flow deflection. These terminals transmit this information to the posterior brain (Jung et al., 2020).

Animals exposed to nanomaterials had fewer neuromast in their head (anterior) and a larger number of them in their caudal (posterior) region (Figure 8). This finding suggested differentiated action by CNFs, and it could have had important biological consequences in the evaluated animals. Neuromats in the head (be it in amphibians or in fish) are sensitive to surface wave movements in water, to detect prey, as well as present better spatial solution due to their greater density. Caudal neuromats (i.e., posterior) are more adept to detecting predators and water disorders (Russell, 1976; Schwartz \& Hasler, 1996; Bleckmann \& Zelick, 2009). Previous studies have also shown effect like that observed in our study, given differences between innervations of anterior and posterior 
neuromats. Hernandez et al. (2006) exposed Danio rerio larvae to different copper concentrations and reported differential hair cell regeneration between neuromats in the head and body of these larvae. Neuromats in the body were unable to regenerate at concentrations higher than $3.18 \mathrm{mg} / \mathrm{L}$, whereas neuromats in the head regenerated at copper levels up to $25.42 \mathrm{mg} / \mathrm{L}$. Similarly, posterior neuromasts were more sensitive in $D$. rerio embryos exposed to caffeine, dichlorvos, 4-nonylphenol and perfluorooctane sulfonic acid (Stengel et al. 2017). Posterior neuromats were more affected by copper sulphate and neomycin than previous neuromats in the aforementioned species after 30-min and 96-h exposure. Anterior neuromats exhibited greater cellular damage (Stengel et al. 2017). In this case, similarly to these findings, our data suggested differentiated action of CNFs on neuromats evaluated in the anterior and posterior regions of $P$. cuvieri tadpoles.

Although the action mechanisms of CNFs have not been explored in-depth in our study, it is tempting to speculate that these nanomaterials have acted in in neuromast populations through different ways. Assumingly, CNFs have affected these cells by competing with calcium ions at the fixation sites, and this process has avoided the flow of ions necessary for signal transduction, as observed by Hudspeth (1983) and Faucher et al. (2006). Thus, damage could be reversible. On the other hand, the reduced number of neuromats observed in the head of tadpoles exposed to CNFs can correspond to permanent damage to these cells because of increased oxidative stress, necrosis, or apoptosis. This hypothesis is supported by results of correlation analyses carried out between the number of neuromats in the head and CNF accumulation in the tested animals (see Table 1), as well as by reports by Olivari et al. (2008), who suggested similar mechanisms to explain the reduced number of neuromats in $D$. rerio larvae exposed to different copper concentrations. On the other hand, the increased number of neuromats observed in groups exposed to CNFs can be a physiological compensation mechanism to balance damages caused by nanomaterials to head cells, since the total number of neuromats did not differ between experimental groups (Figure 8C).

\section{CONCLUSION}

Based on the information above, our study confirmed the initial hypotheses and demonstrated that CNFs can accumulate in animals and have negative effects on the health of $P$. cuvieri tadpoles, even at short-term exposure, at environmentally relevant concentrations. The induction of nutritional deficit, oxidative stress and cyto-and neurotoxic effects are factors affecting these animals' growth and development. However, it is necessary accepting that our results are only the "tip of the iceberg"; therefore, it is essential conducting further investigations to evaluate the biological impacts of CNFs on anurofauna. Limitations of our study are the starting point for future research. It is interesting further evaluating the long-term CBF's effects and their impact on other 
507 physiological functions of the assessed model, as well as identifying and featuring possible damages

508 caused by it in other amphibian species. This finding will be especially important to expand our

509 knowledge about the action mechanisms of these pollutants. This information will be an important

510 basis to assess ecotoxicological risks associated with the presence and dispersion of these pollutants

511 in freshwater ecosystems and, their impact on anurofauna.

\section{ACKNOWLEDGMENT}

The authors are grateful to the Brazilian National Research Council (CNPq) (Brazilian research agency) (proc. N. 426531/2018-3) and to Instituto Federal Goiano for the financial support

516 (Proc. N. 23219.000002.2021-81). The authors also acknowledge Laboratório Multiusuário de

517 Microscopia de Alta Resolução (LabMic) (Universidade Federal de Goiás/Brazil) for their collaboration

518 to the CNFs featuring process. Malafaia G. holds productivity scholarship granted by CNPq (proc.

519 n. 307743/2018-7).

\section{COMPLIANCE WITH ETHICAL STANDARDS}

Conflict of interest: The authors declare no conflict of interest.

Ethical approval: All experimental procedures were carried out in compliance with ethical guidelines on animal experimentation. Meticulous efforts were made to assure that animals suffered the least possible and to reduce external sources of stress, pain and discomfort. The current study did not exceed the number of animals necessary to produce trustworthy scientific data. This article does not refer to any study with human participants performed by any of the authors.

\section{REFERENCES}

Abdo, H. S., Khalil, K. A., El-Rayes, M. M., Marzouk, W. W., Hashem, A. F. M., \& Abdel-Jaber, G. T. (2020). Ceramic nanofibers versus carbon nanofibers as a reinforcement for magnesium metal matrix to improve the mechanical properties. Journal of King Saud UniversityEngineering Sciences, 32(5), 346-350. tadpoles' behavior? A study conducted with neotropical tadpole species belonging to order anura (Physalaemus cuvieri). Journal of Hazardous Materials, 391, 122214. 
Araújo, A. P. C., de Melo, N. F. S., de Oliveira Junior, A. G., Rodrigues, F. P., Fernandes, T., de Andrade Vieira, J. E., ... \& Malafaia, G. (2020a). How much are microplastics harmful to the health of amphibians? A study with pristine polyethylene microplastics and Physalaemus cuvieri. Journal of hazardous materials, 382, 121066.

Araújo, A. P. C., Gomes, A. R., \& Malafaia, G. (2020b). Hepatotoxicity of pristine polyethylene microplastics in neotropical physalaemus cuvieri tadpoles (Fitzinger, 1826). Journal of Hazardous Materials, 386, 121992.

Aziz, Z. A. A., Mohd-Nasir, H., Mohd Setapar, S. H., Peng, W. L., Chuo, S. C., Khatoon, A., ... \& Ahmad, A. (2019). Role of nanotechnology for design and development of cosmeceutical: application in makeup and skin care. Frontiers in Chemistry, 7, 739.

Benedict's qualitative glucose reagent as a biuret reagent. Anal. Chem. v.29, p.1491-1495, 1957.

Bhagyaraj, S. M., \& Oluwafemi, O. S. (2018). Nanotechnology: the science of the invisible. In Synthesis of inorganic nanomaterials (pp. 1-18). Woodhead Publishing.

Bharatraj, D. K., \& Yathapu, S. R. (2018). Nutrition-pollution interaction: An emerging research area. The Indian journal of medical research, 148(6), 697.

Bleckmann H, Zelick R (2009) Lateral line system of fish. Integrative Zool 4:13-25.

Bottini, M., Bruckner, S., Nika, K., Bottini, N., Bellucci, S., Magrini, A., ... \& Mustelin, T. (2006). Multi-walled carbon nanotubes induce T lymphocyte apoptosis. Toxicology letters, 160(2), $121-126$.

Bourdiol, F., Mouchet, F., Perrault, A., Fourquaux, I., Datas, L., Gancet, C., ... \& Flahaut, E. (2013). Biocompatible polymer-assisted dispersion of multi walled carbon nanotubes in water, application to the investigation of their ecotoxicity using Xenopus laevis amphibian larvae. Carbon, 54, 175-191.

Bryan, N. S., \& Grisham, M. B. (2007). Methods to detect nitric oxide and its metabolites in biological samples. Free Radical Biology and Medicine, 43(5), 645-657.

Buto, S., Pollegioni, L., D'Angiuro, L., \& Pilone, M. S. (1994). Evaluation of d $\square$ amino acid oxidase from Rhodotorula gracilis for the production of $\alpha$-keto acids: a reactor system. Biotechnology and bioengineering, 44(11), 1288-1294.

Chang, X. L., Ruan, L., Yang, S. T., Sun, B., Guo, C., Zhou, L., ... \& Yang, M. (2014). Quantification of carbon nanomaterials in vivo: direct stable isotope labeling on the skeleton of fullerene C 60 . Environmental Science: Nano, 1(1), 64-70.

Chaudhary, P., Fatima, F., \& Kumar, A. (2020). Relevance of nanomaterials in food packaging and its advanced future prospects. Journal of Inorganic and Organometallic Polymers and Materials, 30(12), 5180-5192.

Conte, G., Stelitano, S., Policicchio, A., Minuto, F. D., Lazzaroli, V., Galiano, F., \& Agostino, R. G. (2020). Assessment of activated carbon fibers from commercial Kevlar ${ }^{\circledR}$ as nanostructured 
material for gas storage: Effect of activation procedure and adsorption of $\mathrm{CO} 2$ and $\mathrm{CH} 4$. Journal of Analytical and Applied Pyrolysis, 152, 104974.

Cui, H., Kalinin, S. V., Yang, X., \& Lowndes, D. H. (2004). Growth of carbon nanofibers on tipless cantilevers for high resolution topography and magnetic force imaging. Nano Letters, 4(11), 2157-2161.

Damiano, S., Sozio, C., La Rosa, G., Guida, B., Faraonio, R., Santillo, M., \& Mondola, P. (2020). Metabolism Regulation and Redox State: Insight into the Role of Superoxide Dismutase 1. International Journal of Molecular Sciences, 21(18), 6606.

Das, C., Paul, S. S., Saha, A., Singh, T., Saha, A., Im, J., \& Biswas, G. (2020). Silver-Based Nanomaterials as Therapeutic Agents Against Coronaviruses: A Review. International journal of nanomedicine, 15, 9301.

Das, S., Glenn IV, J. H., \& Subramanian, M. (2010). Enantioselective oxidation of $2 \square$ hydroxy carboxylic acids by glycolate oxidase and catalase coexpressed in methylotrophic Pichia pastoris. Biotechnology progress, 26(3), 607-615.

Dashty, M. (2013). A quick look at biochemistry: carbohydrate metabolism. Clinical biochemistry, 46(15), 1339-1352.

De Leon, J. A. D., \& Borges, C. R. (2020). Evaluation of Oxidative Stress in Biological Samples Experiments), (159), e61122.

Dornelles, M. F., \& Oliveira, G. T. (2014). Effect of atrazine, glyphosate and quinclorac on biochemical parameters, lipid peroxidation and survival in bullfrog tadpoles (Lithobates

Din, I. U., Shaharun, M. S., Naeem, A., Alotaibi, M. A., Alharthi, A. I., Bakht, M. A., \& Nasir, Q.

Del-Maestro, R. F., \& McDonald, W. (1985). Oxidative enzymes in tissue homogenates. Handbook of methods for oxygen radical research, 291-296.

De-Oliveira-Miranda, N. E., Maciel, N. M., Lima-Ribeiro, M. S., Colli, G. R., Haddad, C. F. B., \& Collevatti, R. G. (2019). Diversification of the widespread neotropical frog Physalaemus cuvieri in response to Neogene-Quaternary geological events and climate dynamics. Molecular Phylogenetics and Evolution, 132, 67-80. catesbeianus). Archives of Environmental Contamination and Toxicology, 66(3), 415-429.

Dornelles, M. F., \& Oliveira, G. T. (2016). Toxicity of atrazine, glyphosate, and quinclorac in 608 bullfrog tadpoles exposed to concentrations below legal limits. Environmental Science and Pollution Research, 23(2), 1610-1620. 
609 Eason, C., \& O'Halloran, K. (2002). Biomarkers in toxicology versus ecological risk assessment. 610 Toxicology, 181, 517-521.

611 Edmondson, D. (2014). Hydrogen peroxide produced by mitochondrial monoamine oxidase 612 catalysis: biological implications. Current Pharmaceutical Design, 20(2), 155-160.

613 Elgrabli, D., Abella-Gallart, S., Robidel, F., Rogerieux, F., Boczkowski, J., \& Lacroix, G. (2008). 614 Induction of apoptosis and absence of inflammation in rat lung after intratracheal instillation 615 of multiwalled carbon nanotubes. Toxicology, 253(1-3), 131-136.

616 Ellman, G. L., Courtney, K. D., Andres Jr, V., \& Featherstone, R. M. (1961). A new and rapid 617 colorimetric determination of acetylcholinesterase activity. Biochemical pharmacology, 7(2), $618 \quad 88-95$.

Elnemma, E. M. (2004). Spectrophotometric determination of hydrogen peroxide by a hydroquinone-aniline system catalyzed by molybdate. Bulletin of the Korean Chemical Society, 25 (1), 127-129.

Estrela, F. N., Guimarães, A. T. B., Silva, F. G., da Luz, T. M., Silva, A. M., Pereira, P. S., \& Malafaia, G. (2021). Effects of polystyrene nanoplastics on Ctenopharyngodon idella (grass carp) after individual and combined exposure with zinc oxide nanoparticles. Journal of Hazardous Materials, 403, 123879.

Ezemonye, L. I. N., \& Ilechie, I. (2007). Acute and chronic effects of organophosphate pesticides (Basudin) to amphibian tadpoles (Ptychadena bibroni). African Journal of Biotechnology, $6(13)$.

Fabian, F. L. (2019). Advantages and Drawbacks of the Nanotechnology and Biotechnology toward Shaping a Global Sustainable Development. Biosciences Biotechnology Research Asia, 16(4), 693-695.

Firoozi, A. A., Naji, M., Dithinde, M., \& Firoozi, A. A. (2020). A Review: Influence of Potential Nanomaterials for Civil Engineering Projects. Iranian Journal of Science and Technology, Transactions of Civil Engineering, 1-12.

Freixa, A., Acuña, V., Sanchís, J., Farré, M., Barceló, D., \& Sabater, S. (2018). Ecotoxicological effects of carbon based nanomaterials in aquatic organisms. Science of the Total Environment, $619,328-337$.

Frost DR. Amphibian Species of the World: an Online Reference. Version 6.0. Available in: http://research.amnh.org/vz/herpetology/amphibia/. Access on: 11 march. 2017.

Fytianos, G., Rahdar, A., \& Kyzas, G. Z. (2020). Nanomaterials in Cosmetics: Recent Updates. Nanomaterials, 10(5), 979. 
643

644

645

646

647

648

649

650

651

652

653

654

655

656

657

658

659

660

661

662

663

664

665

666

667

668

669

670

671

672

673

674

675

676

Gao, C., Zhang, W., Ma, C., Liu, P., \& Xu, P. (2011). Kinetic resolution of 2-hydroxybutanoate racemic mixtures by NAD-independent L-lactate dehydrogenase. Bioresource technology, $102(7), 4595-4599$.

Gendron, A. D., Bishop, C. A., Fortin, R., \& Hontela, A. (1997). In vivo testing of the functional integrity of the corticosterone $\square$ producing axis in mudpuppy (amphibia) exposed to chlorinated hydrocarbons in the wild. Environmental Toxicology and Chemistry: An International Journal, 16(8), 1694-1706.

Gomes, A. R., Chagas, T. Q., Silva, A. M., de Lima Rodrigues, A. S., da Luz, T. M., de Andrade Vieira, J. E., \& Malafaia, G. (2021). Trophic transfer of carbon nanofibers among eisenia fetida, danio rerio and oreochromis niloticus and their toxicity at upper trophic level. Chemosphere, 263, 127657.

GORNALL, A.G.; BARDAWILL, C.J.; DAVID, M. M. Determination of serum proteins by means of the biuret reaction. J. Biol. Chem. v.177, p.751-766, 1949.

Gosner KL. A simplified table for staging anuran embryos and larvae with notes on identification. Herpetologica, 16:183-1901960.

Goto, H., Saito, T., Teraoka, K., Murakami, S., Kitazawa, M., Ohta, R., \& Tanemura, M. (2014). Biofunctionalization of carbon nanofiber tips for scanning probe microscopy using thin $\mathrm{Au}$ coating and immobilized biorecognition molecules. Carbon, 68, 638-645.

Green, D. M., Lannoo, M. J., Lesbarrères, D., \& Muths, E. (2020). Amphibian population declines: 30 years of progress in confronting a complex problem. Herpetologica, 76(2), 97-100.

Guimarães, A. T. B., Charlie-Silva, I., \& Malafaia, G. (2020). TOXIC EFFECTS OF NATURALLY-AGED MICROPLASTICS ON ZEBRAFISH JUVENILES: A MORE REALISTIC APPROACH TO PLASTIC POLLUTION IN FRESHWATER ECOSYSTEMS. Journal of Hazardous Materials, 124833.

Harris, G. G., Frishkopf, L. S., \& Flock, A. (1970). Receptor potentials from hair cells of the lateral line. Science, 167 (3914), 76-79.

HENRY, R. J.; SOBEL, C.; BERKMAN, S. Interferences with biuret methods for serum proteins. Use of Bucolo, G., \& David, H. (1973). Quantitative determination of serum triglycerides by the use of enzymes. Clinical chemistry, 19(5), 476-482.

Herek, J. S., Vargas, L., Trindade, S. A. R., Rutkoski, C. F., Macagnan, N., Hartmann, P. A., \& Hartmann, M. T. (2020). Can environmental concentrations of glyphosate affect survival and cause malformation in amphibians? Effects from a glyphosate-based herbicide on Physalaemus cuvieri and P. gracilis (Anura: Leptodactylidae). Environmental Science and Pollution Research, 1-12.

Hernandez PP, Moreno V, Olivari FA, Allende ML (2006) Sub-lethal concentrations of waterborne copper are toxic to lateral line neuromastos in zebrafish (Danio rerio). Hear Res 213:1-10 
677 Hernandez, K., Berenguer-Murcia, A., C Rodrigues, R., \& Fernandez-Lafuente, R. (2012). Hydrogen peroxide in biocatalysis. A dangerous liaison. Current Organic Chemistry, 16(22), 2652-2672.

Hocking, D. J., \& Babbitt, K. J. (2014). Amphibian contributions to ecosystem services. Herpetological conservation and biology.

Ighodaro, O. M., \& Akinloye, O. A. (2018). First line defence antioxidants-superoxide dismutase (SOD), catalase (CAT) and glutathione peroxidase (GPX): Their fundamental role in the entire antioxidant defence grid. Alexandria journal of medicine, 54(4), 287-293.

International Union for Conservation of Nature (IUCN). Red List of Threatened Species 2020. https://www.iucnredlist.org/search?query =Physalaemus\%20cuvieri\&searchType = species. Access on: 30 Dec. 2020.

Itri, R., Junqueira, H. C., Mertins, O., \& Baptista, M. S. (2014). Membrane changes under oxidative stress: the impact of oxidized lipids. Biophysical reviews, 6(1), 47-61.

Jaworski, K., Sarkadi-Nagy, E., Duncan, R. E., Ahmadian, M., \& Sul, H. S. (2007). Regulation of triglyceride metabolism. IV. Hormonal regulation of lipolysis in adipose tissue. American Journal of Physiology-Gastrointestinal and Liver Physiology, 293(1), G1-G4.

Jung, J., Serrano-Rojas, S. J., \& Warkentin, K. M. (2020). Multimodal mechanosensing enables treefrog embryos to escape egg-predators. Journal of Experimental Biology, 223(24).

Kaul, S., Gulati, N., Verma, D., Mukherjee, S., \& Nagaich, U. (2018). Role of nanotechnology in cosmeceuticals: a review of recent advances. Journal of pharmaceutics, 2018.

Keller, A. A., Vosti, W., Wang, H., \& Lazareva, A. (2014). Release of engineered nanomaterials from personal care products throughout their life cycle. Journal of nanoparticle research, $16(7), 2489$.

Khan, F. R., Syberg, K., Shashoua, Y., \& Bury, N. R. (2015). Influence of polyethylene microplastic beads on the uptake and localization of silver in zebrafish (Danio rerio). Environmental pollution, 206, 73-79.

Kim, K. H., Yeon, S. M., Kim, H. G., Lee, H., Kim, S. K., Han, S. H., ... \& Yuk, S. H. (2014). Single-walled carbon nanotubes induce cell death and transcription of TNF- $\alpha$ in macrophages without affecting nitric oxide production. Inflammation, 37(1), 44-54.

Krupa, P. M., McMurry, S. T., Minghetti, M., \& Belden, J. B. (2020). Effects of Copper on the Neuromasts of Xenopus Laevis. Archives of Environmental Contamination and Toxicology, 110.

Kumar, R., Aadil, K. R., Ranjan, S., \& Kumar, V. B. (2020). Advances of nanotechnology and nanomaterials based strategies for neural tissue engineering. Journal of Drug Delivery Science and Technology, 101617. 
Lake, C. L., \& Lake, P. D. (2014). Carbon Nanofiber Multifunctional Mat. In Nanotube Superfiber Materials (pp. 313-331). William Andrew Publishing.

Lannoo, M. J. (1999). Integration: nervous and sensory systems. In Tadpoles: The Biology of Anuran Larvae (ed. McDiarmid, R. and Altig, R.), pp. 149-169. Chicago, IL: University of Chicago Press.

Larrick, J. W., \& Wright, S. C. (1990). Cytotoxic mechanism of tumor necrosis factor $\square \alpha$. The FASEB Journal, 4(14), 3215-3223.

Laster, S. M., Wood, J. G., \& Gooding, L. R. (1988). Tumor necrosis factor can induce both apoptic and necrotic forms of cell lysis. The Journal of Immunology, 141(8), 2629-2634.

Lee, J. N., Dutta, R. K., Maharjan, Y., Liu, Z. Q., Lim, J. Y., Kim, S. J., ... \& Park, R. (2018). Catalase inhibition induces pexophagy through ROS accumulation. Biochemical and biophysical research communications, 501(3), 696-702.

Lee, J. W., Choi, Y. C., Kim, R., \& Lee, S. K. (2015). Multiwall carbon nanotube-induced apoptosis and antioxidant gene expression in the gills, liver, and intestine of Oryzias latipes. BioMed research international, 2015.

Li, B., Stribley, J. A., Ticu, A., Xie, W., Schopfer, L. M., Hammond, P., ... \& Lockridge, O. (2000). Abundant tissue butyrylcholinesterase and its possible function in the acetylcholinesterase knockout mouse. Journal of neurochemistry, 75(3), 1320-1331.

Li, S., He, P., Dong, J., Guo, Z., \& Dai, L. (2005). DNA-directed of carbon self-assembling nanotubes. J Am Chem Soc, 127, 14-15.

Liu, Z. G., \& Jiao, D. (2020). Necroptosis, tumor necrosis and tumorigenesis. Cell Stress, 4(1), 1.

Lusher, A. L., Mchugh, M., \& Thompson, R. C. (2013). Occurrence of microplastics in the gastrointestinal tract of pelagic and demersal fish from the English Channel. Marine pollution bulletin, 67(1-2), 94-99.

Madear, C., Dunca, E. C., \& Madear, G. (2020, December). Soil Remediation Strategies based on Risk Assessment Approach. In IOP Conference Series: Earth and Environmental Science (Vol. 609, No. 1, p. 012094). IOP Publishing.

Maharajan, K., Muthulakshmi, S., Nataraj, B., Ramesh, M., \& Kadirvelu, K. (2018). Toxicity assessment of pyriproxyfen in vertebrate model zebrafish embryos (Danio rerio): a multi biomarker study. Aquatic Toxicology, 196, 132-145.

Martynova, E. A., \& Gapparov, M. M. (2007). Energy-proteolysis and regulation of protein metabolism. Voprosy pitaniia, 76(1), 4.

Melvin, S. D., Lanctôt, C. M., Craig, P. M., Moon, T. W., Peru, K. M., Headley, J. V., \& Trudeau, V. L. (2013). Effects of naphthenic acid exposure on development and liver metabolic processes in anuran tadpoles. Environmental pollution, 177, 22-27. 
MIJARES, A.; RODRIGUES, M.T.; BALDO, D. Physalaemus cuvieri. In: IUCN 2011. IUCN Red List of Threatened Species. Version 2011.2. <www.iucnredlist.org >. 2010.

Miranda NEO, Maciel NM, Ribeiro MSL, Colli GR, Haddad FB, Collevatti RG. Diversification of the widespread neotropical frog Physalaemus cuvieri in response to Neogene-Quaternary geological events and climate dynamics. Molecular Phylogenetics and Evolution, 132: 67-80, 2019.

Mogdans, J. (2019). Sensory ecology of the fish lateral $\square$ line system: Morphological and physiological adaptations for the perception of hydrodynamic stimuli. Journal of Fish Biology, 95(1), 53-72.

Mohamed, A. (2019). Synthesis, characterization, and applications carbon nanofibers. In Carbonbased nanofillers and their rubber nanocomposites (pp. 243-257). Elsevier.

Mohr C, Gorner P (1996) Innervation patterns of the lateral line stitches of the clawed frog, Xenopus laevis, and their reorganization during metamorphosis. Brain Behav Evol 48(2):5569

Montalvão, M. F., Guimarães, A. T. B., de Lima Rodrigues, A. S., \& Malafaia, G. (2021). Carbon nanofibers are bioaccumulated in Aphylla williamsoni (Odonata) larvae and cause REDOX imbalance and changes of acetylcholinesterase activity. Science of The Total Environment, 143991.

Mouchet F, Landois P, Pinelli E, Flahaut E, Gauthier L: Carbon nanotubes in the environment and their potential ecotoxicity: Context and state of the art. Ecotoxicité des nanotubes de carbone dans l'environnement : contexte et état de l'art. Env. Risques \& Santé 8(1), 47-55 (2009).

Mouchet, F., Landois, P., Datsyuk, V., Puech, P., Pinelli, E., Flahaut, E., \& Gauthier, L. (2011). International amphibian micronucleus standardized procedure (ISO 21427-1) for in vivo evaluation of double-walled carbon nanotubes toxicity and genotoxicity in water. Environmental toxicology, 26(2), 136-145.

Mouchet, F., Landois, P., Flahaut, E., Pinelli, E., \& Gauthier, L. (2007). Assessment of the potential in vivo ecotoxicity of double-walled carbon nanotubes (DWNTs) in water, using the amphibian Ambystoma mexicanum. Nanotoxicology, 1(2), 149-156.

Mouchet, F., Landois, P., Puech, P., Pinelli, E., Flahaut, E., \& Gauthier, L. (2010). Carbon nanotube ecotoxicity in amphibians: assessment of multiwalled carbon nanotubes and comparison with doublewalled carbon nanotubes. Nanomedicine, 5(6), 963-974.

Nezhadheydari, H., Tavabe, K. R., Mirvaghefi, A., Heydari, A., \& Frinsko, M. (2019). Effects of different concentrations of Fe3O4@ ZnO and Fe3O4@CNT magnetic nanoparticles separately and in combination on aquaculture wastewater treatment. Environmental Technology \& Innovation, 15, 100414.

Ni, H. M., McGill, M. R., Chao, X., Woolbright, B. L., Jaeschke, H., \& Ding, W. X. (2016). Caspase inhibition prevents tumor necrosis factor- $\alpha$-induced apoptosis and promotes necrotic cell 
death in mouse hepatocytes in vivo and in vitro. The American journal of pathology, 186(10), 2623-2636.

O'Halloran, K. (2006). Toxicological considerations of contaminants in the terrestrial environment for ecological risk assessment. Human and Ecological Risk Assessment, 12(1), 74-83.

Ohkawa, H., Ohishi, N., \& Yagi, K. (1979). Assay for lipid peroxides in animal tissues by thiobarbituric acid reaction. Analytical biochemistry, 95(2), 351-358.

Olivari FA, Hernández PP, Allende ML (2008) Acute copper exposure induces oxidative stress and cell death in lateral line hair cells of zebrafish larvae. Brain Res 1244:1-12

Palit, S., \& Hussain, C. M. (2020). Functionalization of nanomaterials for industrial applications: recent and future perspectives. In Handbook of Functionalized Nanomaterials for Industrial Applications (pp. 3-14). Elsevier.

Patlolla, A., Knighten, B., \& Tchounwou, P. (2010). Multi-walled carbon nanotubes induce cytotoxicity, genotoxicity and apoptosis in normal human dermal fibroblast cells. Ethnicity \& disease, 20(1 Suppl 1), S1.

Petersen, E. J., Flores-Cervantes, D. X., Bucheli, T. D., Elliott, L. C., Fagan, J. A., Gogos, A., ... \& Plata, D. studies, and future prospects. Environmental science $\&$ technology, 50(9), 4587-4605.

Pollegioni, L., \& Molla, G. (2011). New biotech applications from evolved D-amino acid oxidases. Trends in biotechnology, 29(6), 276-283.

Pollegioni, L., Piubelli, L., \& Molla, G. (2009). Cholesterol oxidase: biotechnological applications. The FEBS journal, 276(23), 6857-6870.

Pupin, N. C., Gasparini, J. L., Bastos, R. P., Haddad, C. F., \& Prado, C. (2010). Reproductive biology of an endemic Physalaemus of the Brazilian Atlantic forest, and the trade-off between clutch and egg size in terrestrial breeders of the P. signifer group. The Herpetological Journal, 20(3), 147-156.

Rand, G. M. (Ed.). (2020). Fundamentals of aquatic toxicology: effects, environmental fate and risk assessment. CRC press.

Ransy, C., Vaz, C., Lombès, A., \& Bouillaud, F. (2020). Use of H2O2 to Cause Oxidative Stress, the Catalase Issue. International Journal of Molecular Sciences, 21(23), 9149.

Ravichandran, P., Periyakaruppan, A., Sadanandan, B., Ramesh, V., Hall, J. C., Jejelowo, O., \& transmission in the inner ear. Annual review of cell biology, 4(1), 63-92. 
812 Rohman, F., Permana, H., Akhsani, F., Wangkulangkul, S., \& Priambodo, B. (2020, April). The 813 amphibians diversity as bioindicator of aquatic ecosystem at Sumber Taman, Malang, East 814 Java. In AIP Conference Proceedings (Vol. 2231, No. 1, p. 040016). AIP Publishing LLC.

Roy, D. (2002). Amphibians as environmental sentinels. Journal of biosciences, 27(3), 187.

Russell, I. J. (1976). Amphibian lateral line receptors. In Frog neurobiology (pp. 513-550). Springer, Berlin, Heidelberg.

Rutkoski, C. F., Macagnan, N., Folador, A., Skovronski, V. J., do Amaral, A. M., Leitemperger, J. W., ... \& Hartmann, M. T. (2020). Cypermethrin-and fipronil-based insecticides cause biochemical changes in Physalaemus gracilis tadpoles. Environmental Science and Pollution Research, 1-11.

Sachett, A., Bevilaqua, F., Chitolina, R., Garbinato, C., Gasparetto, H., Dal Magro, J., ... \& Siebel, A. M. (2018). Ractopamine hydrochloride induces behavioral alterations and oxidative status imbalance in zebrafish. Journal of Toxicology and Environmental Health, Part A, 81(7), 194-201.

Salehcheh, M., Alboghobeish, S., Dehghani, M. A., \& Zeidooni, L. (2020). Multi-walled carbon nanotubes induce oxidative stress, apoptosis, and dysfunction in isolated rat heart mitochondria: protective effect of naringin. Environmental Science and Pollution Research, 110.

Sand, O., Ozawa, S., \& Hagiwara, S. (1975). Electrical and mechanical stimulation of hair cells in the mudpuppy. Journal of comparative physiology, 102(1), 13-26.

Saria, R., Mouchet, F., Perrault, A., Flahaut, E., Laplanche, C., Boutonnet, J. C., ... \& Gauthier, L. (2014). Short term exposure to multi-walled carbon nanotubes induce oxidative stress and DNA damage in Xenopus laevis tadpoles. Ecotoxicology and Environmental Safety, 107, 22-29.

Saria, R., Mouchet, F., Perrault, A., Flahaut, E., Laplanche, C., Boutonnet, J. C., ... \& Gauthier, L. (2014). Short term exposure to multi-walled carbon nanotubes induce oxidative stress and DNA damage in Xenopus laevis tadpoles. Ecotoxicology and Environmental Safety, 107, $22-$ 29. PEDOT composite films as novel microelectrode for neural interfaces and biosensing. Biosensors and Bioelectronics, 165, 112413.

Saxena, U., Chakraborty, M., \& Goswami, P. (2011). Covalent immobilization of cholesterol oxidase on self-assembled gold nanoparticles for highly sensitive amperometric detection of cholesterol in real samples. Biosensors and Bioelectronics, 26(6), 3037-3043. 
Schwab F, Bucheli TD, Lukhele LP, Magrez A, Nowack B, Sigg L, Knauer K. Are Carbon Nanotube Effects on Green Algae Caused by Shading and Agglomeration? Environmental Science \& Technology, 45: 6136-6144, 2011.

Schwartz E, Hasler AD (1966) Perception of surface waves by the blackstripe topminnow, Fundulus notatus. J Fish Res Board Can 23:1331-1352

Senthamizhan, A., Balusamy, B., \& Uyar, T. (2020). Recent progress on designing electrospun nanofibers for colorimetric biosensing applications. Current Opinion in Biomedical Engineering, 13, 1-8.

Shafiq, M., Anjum, S., Hano, C., Anjum, I., \& Abbasi, B. H. (2020). An Overview of the Applications of Nanomaterials and Nanodevices in the Food Industry. Foods, 9 (2), 148.

Shen, Z. L., Nie, H. Y., Wang, H. F., Yang, B., Zhong, L. J., Zou, X. J., ... \& Jia, G. (2010). Two types of MWNTs with different surface modifications induce differential expression of proteins in RAW264. 7 cells. Beijing da xue xue bao. Yi xue ban= Joumal of Peking University. Health sciences, $42(3), 345$.

Siddique, S., \& Chow, J. C. (2020). Application of nanomaterials in biomedical imaging and cancer therapy. Nanomaterials, 10(9), 1700.

Siebum, A., van Wijk, A., Schoevaart, R., \& Kieboom, T. (2006). Galactose oxidase and alcohol oxidase: Scope and limitations for the enzymatic synthesis of aldehydes. Journal of Molecular Catalysis B: Enzymatic, 41(3-4), 141-145.

Sies, H. (2020). Oxidative stress: Concept and some practical aspects. Antioxidants, 9(9), 852.

Sies, H., \& Jones, D. P. (2020). Reactive oxygen species (ROS) as pleiotropic physiological signalling agents. Nature Reviews Molecular Cell Biology, 1-21.

Silva, F. F. D., Silva, J. M. D., Silva, T. D. J. D., Tenorio, B. M., Tenorio, F. D. C. A. M., Santos, E. L., ... \& Soares, E. C. (2020). Evaluation of Nile tilapia (Oreochromis niloticus) fingerlings exposed to the pesticide pyriproxyfen. Latin american journal of aquatic research, 48(5), 826-835.

Singh, N. B. (2020). Properties of cement and concrete in presence of nanomaterials. In Smart Nanoconcretes and Cement-Based Materials (pp. 9-39). Elsevier.

Singh, S., Pandey, S. K., \& Vishwakarma, N. (2020). Functional nanomaterials for the cosmetics industry. In Handbook of Functionalized Nanomaterials for Industrial Applications (pp. 717730). Elsevier.

Sinha, A. K. (1972). Colorimetric assay of catalase. Analytical biochemistry, 47(2), 389-394.

Sohaebuddin, S. K., Thevenot, P. T., Baker, D., Eaton, J. W., \& Tang, L. (2010). Nanomaterial cytotoxicity is composition, size, and cell type dependent. Particle and fibre toxicology, 7 (1), 22. 
879 Soneja, A., Drews, M., \& Malinski, T. (2005). Role of nitric oxide, nitroxidative and oxidative stress in wound healing. Pharmacological reports, 57, 108.

Srivastava, R. K., Pant, A. B., Kashyap, M. P., Kumar, V., Lohani, M., Jonas, L., \& Rahman, Q. (2011). Multi-walled carbon nanotubes induce oxidative stress and apoptosis in human lung cancer cell line-A549. Nanotoxicology, 5(2), 195-207.

Strong, R., Martin, F. L., Jones, K. C., Shore, R. F., \& Halsall, C. J. (2017). Subtle effects of environmental stress observed in the early life stages of the Common frog, Rana temporaria. Scientific reports, $7(1), 1-13$.

Taran, M., Safaei, M., Karimi, N., \& Almasi, A. (2020). Benefits and Application of Nanotechnology in Environmental Science: an Overview.

Tavabe, K. R., Yavar, M., Kabir, S., Akbary, P., \& Aminikhoei, Z. (2020). Toxicity effects of multi-walled carbon nanotubes (MWCNTs) nanomaterial on the common carp (Cyprinus carpio L. 1758) in laboratory conditions. Comparative Biochemistry and Physiology Part C: Toxicology \& Pharmacology, 237, 108832.

Thomas, S., Grohens, Y., \& Pottathara, Y. B. (Eds.). (2019). Industrial applications of nanomaterials. Elsevier.

Tschopp, J., \& Schroder, K. (2010). NLRP3 inflammasome activation: The convergence of multiple signalling pathways on ROS production?. Nature reviews immunology, 10(3), 210-215.

Turner, N. J. (2011). Enantioselective oxidation of C-O and C-N bonds using oxidases. Chemical reviews, 111(7), 4073-4087.

Van-Herreweghe, F., Festjens, N., Declercq, W., \& Vandenabeele, P. (2010). Tumor necrosis factor-mediated cell death: to break or to burst, that's the question. Cellular and Molecular Life Sciences, $67(10)$, 1567-1579.

Wagner, N., Züghart, W., Mingo, V., \& Lötters, S. (2014). Are deformation rates of anuran developmental stages suitable indicators for environmental pollution? Possibilities and limitations. Ecological indicators, 45, 394-401. 
Walkley, A.; Black, I. A. An examination of the Degtjareff method for determining soil organic matter and a proposed modification of the chromic acid titration method. Soil Science, Baltimore, v. 37, n. 1, p. 29 . 38, Jan./ June 1934.

Wang, H., Yang, S. T., Cao, A., \& Liu, Y. (2013). Quantification of carbon nanomaterials in vivo. Accounts of chemical research, 46(3), 750-760.

Wang, K., Liu, Q., Guan, Q. M., Wu, J., Li, H. N., \& Yan, J. J. (2011). Enhanced direct electrochemistry of glucose oxidase and biosensing for glucose via synergy effect of graphene and CdS nanocrystals. Biosensors and Bioelectronics, 26(5), 2252-2257.

Wang, L., Wu, W. M., Bolan, N. S., Tsang, D. C., Li, Y., Qin, M., \& Hou, D. (2020). Environmental fate, toxicity and risk management strategies of nanoplastics in the environment: Current status and future perspectives. Journal of hazardous materials, 401, 123415.

Wang, X., Guo, J., Chen, T., Nie, H., Wang, H., Zang, J., ... \& Jia, G. (2012). Multi-walled carbon nanotubes induce apoptosis via mitochondrial pathway and scavenger receptor. Toxicology in Vitro, 26(6), 799-806.

Wang, X., Guo, J., Chen, T., Nie, H., Wang, H., Zang, J., ... \& Jia, G. (2012). Multi-walled carbon nanotubes induce apoptosis via mitochondrial pathway and scavenger receptor. Toxicology in Vitro, 26(6), 799-806.

Wang, Z., Zhang, K., Zhao, J., Liu, X., \& Xing, B. (2010). Adsorption and inhibition of butyrylcholinesterase by different engineered nanoparticles. Chemosphere, 79(1), 86-92.

Wingfield, J. C., Maney, D. L., Breuner, C. W., Jacobs, J. D., Lynn, S., Ramenofsky, M., \& Richardson, R. D. (1998). Ecological bases of hormone-behavior interactions: the “emergency life history stage”. American Zoologist, 38(1), 191-206.

Yadav, D., Amini, F., \& Ehrmann, A. (2020). Recent advances in carbon nanofibers and their applications-a review. European Polymer Journal, 109963.

Yao, X., \& Cadwell, K. (2020). Tumor Necrosis Factor- $\alpha$-Induced Apoptosis in the Intestinal Epithelium due to Chronic Nuclear Factor Kappa B Signaling Is Mediated by Receptor Interacting Serine/Threonine Kinase 1. Cellular and molecular gastroenterology and hepatology, 9(2), 337.

Zeb, S., Ullah, I., Karim, A., Muhammad, W., Ullah, N., Khan, M., \& Komal, W. (2019). A Review on Nanotechnology Applications in Electric Components. Nanotechnology, 2(2).

Zhao, J., Luo, W., Xu, Y., Ling, J., \& Deng, L. (2020). Potential reproductive toxicity of multi-walled carbon nanotubes and their chronic exposure effects on the growth and development of Xenopus tropicalis. Science of The Total Environment, 142652. 
945 Zhao, J., Xie, G., Xu, Y., Zheng, L., \& Ling, J. (2020). Accumulation and toxicity of multi-walled

946 carbon nanotubes in Xenopus tropicalis tadpoles. Chemosphere, 127205.

947 Zhou, K., Zhu, Y., Yang, X., \& Li, C. (2010). Electrocatalytic Oxidation of Glucose by the Glucose

948 Oxidase Immobilized in Graphene $\square$ Au $\square$ Nafion Biocomposite. Electroanalysis: An

949 International Journal Devoted to Fundamental and Practical Aspects of Electroanalysis, $950 \quad 22(3), 259-264$.

951 Zhu, L., Chang, D. W., Dai, L., \& Hong, Y. (2007). DNA damage induced by multiwalled carbon 952 nanotubes in mouse embryonic stem cells. Nano letters, 7 (12), 3592-3597. 